\title{
Machine Learning and LPWAN Based Internet of Things Applications in Healthcare Sector during COVID-19 Pandemic
}

\author{
Zeeshan Ali Khan ${ }^{1}$, Ubaid Abbasi ${ }^{2}$ a and Sung Won Kim ${ }^{3, *}$ (I) \\ 1 Department of Computer Science, National University of Computer and Emerging Sciences, \\ Lahore 54770, Pakistan; zeeshanali.khan@nu.edu.pk \\ 2 Department of Computer Science, GPRC, Grand Priaire, AB T8V 4C4, Canada; UAbbasi@gprc.ab.ca \\ 3 Department of Information and Communication Engineering, Yeungnam University, Gyeongsan 38541, Korea \\ * Correspondence: swon@yu.ac.kr
}

check for

updates

Citation: Khan, Z.A.; Abbasi, U.; Kim, S.W. Machine Learning and LPWAN Based Internet of Things Applications in Healthcare Sector during COVID-19 Pandemic.

Electronics 2021, 10, 1615. https:// doi.org/10.3390/electronics10141615

Academic Editors: Jorge Navarro Ortiz, Cristina Cervelló-Pastor, Iván Vidal, Jasone Astorga and Juan-Carlos Cano

Received: 25 May 2021

Accepted: 28 June 2021

Published: 6 July 2021

Publisher's Note: MDPI stays neutral with regard to jurisdictional claims in published maps and institutional affiliations.

Copyright: (c) 2021 by the authors. Licensee MDPI, Basel, Switzerland. This article is an open access article distributed under the terms and conditions of the Creative Commons Attribution (CC BY) license (https:/ / creativecommons.org/licenses/by/ $4.0 /)$.

\begin{abstract}
Low power wide area networks (LPWAN) are comprised of small devices having restricted processing resources and limited energy budget. These devices are connected with each other using communication protocols. Considering their available resources, these devices can be used in a number of different Internet of Things (IoT) applications. Another interesting paradigm is machine learning, which can also be integrated with LPWAN technology to embed intelligence into these IoT applications. These machine learning-based applications combine intelligence with LPWAN and prove to be a useful tool. One such IoT application is in the medical field, where they can be used to provide multiple services. In the scenario of the COVID-19 pandemic, the importance of LPWAN-based medical services has gained particular attention. This article describes various COVID-19-related healthcare services, using the the applications of machine learning and LPWAN in improving the medical domain during the current COVID-19 pandemic. We validate our idea with the help of a case study that describes a way to reduce the spread of any pandemic using LPWAN technology and machine learning. The case study compares k-Nearest Neighbors (KNN) and trust-based algorithms for mitigating the flow of virus spread. The simulation results show the effectiveness of KNN for curtailing the COVID-19 spread.
\end{abstract}

Keywords: LPWAN; IoT; healthcare; machine learning; pandemic diseases

\section{Introduction}

Gartner predicted that low power short range networks will be significantly large in number by 2025, and they will be the enabling technology for the Internet of Things (IoT) [1]. LPWAN-based IoT applications are developed in the fields of healthcare, smart grid, and transport. These networks are comprised of very small devices which can be worn on the skin or integrated with domestic appliances. However, these devices have limited processing and restricted energy budget because of small batteries. These devices are used to implement the concept of connecting anyone, anything, anywhere, and any network. This helps in realizing the automation in the fields of healthcare, smart grid, and transport [2]. Due to the developments in the domains of machine learning, artificial intelligence, and communication technologies, it is highly probable that these networks would be used to further innovate the existing applications [3]. LPWAN enables the connected devices to send the sensed physical parameters to the centralized gateway, which may make appropriate decisions using machine learning algorithms. The constraints on applications are energy efficiency and low complexity for a salable network, with nodes joining and leaving frequently.

LPWAN is a new connectivity option for the IoT applications, which will use features of the cellular and short range wireless devices. Traditionally, the IoT applications are realized using short range wireless devices, whereas the wide area coverage is provided by the cellular network. However, LPWAN combines the features of both types of networks. 
In short, the goal of LPWAN is to provide long range communication with low processing requirements. This enables many new IoT applications which may benefit from this connectivity option. For IoT and M2M, LPWAN technology has extensive capacity to support numerous applications involving constrained devices. LPWAN applications lie in the domains of smart grid, smart city, personal IoT applications, smart metering, etc. [4].

One of the most attractive IoT applications of LPWAN lies in the field of healthcare. LPWAN can implement various IoT healthcare applications and provide appropriate services to the end-user. The applications include the monitoring of vital signs, and the received data can be used to implement various services [5]. Hence, different medical diagnostic and imaging devices and sensors can be regarded as a major part of the IoT application. These healthcare services can help in reducing cost, better protect the healthcare providers, and smooth patient experience. The healthcare provider can remotely monitor a patient and provide appropriate support using available services. Further, they can get a reduction in cost as well. The patient can get better care $24 / 7$ as they are constantly monitored remotely [6].

The data obtained from LPWAN-based IoT healthcare applications are tremendous and can be used to predict various parameters. In this context, machine learning is an important tool [7]. Machine learning is a part of Artificial Intelligence (AI) and is used to derive a mathematical model from a set of data. This mathematical model is easily understood by human beings and can be used to make future decisions. In the context of IoT-based healthcare applications, the data can be gathered in a central gateway. Although the devices have limited processing resources, central gateways can be used to implement machine learning algorithms. These gateways can then generate mathematical models from these datasets for future purposes. Hence, it is an important mathematical tool which needs to be considered [8].

In the end of 2019, the coronavirus pandemic (COVID-19) was originated from Wuhan, China [9]. The World Health Organization (WHO) declared it a public health emergency and it changed the way the world used to be. One of the recommended preventive measures include social distancing, as it is transmitted by person-to-person contact. LPWAN-based IoT healthcare services are particularly important in this scenario, as they reduce the personto-person contact, thus reducing the chances of the spread of this disease [10]. Further, the healthcare provider can benefit from LPWAN technology as it can reduce the healthcare provider's contact with the patient. Hence, it can help to reduce the spread of the disease to paramedical staff. LPWAN technology coupled with machine learning can be used to better predict the disease as well.

In this paper, we give a survey of existing IoT-based healthcare applications and how they can be used in the COVID-19 scenario. We discuss various services and discuss how machine learning can help in current pandemic situation. Finally, we discuss a case study using $\mathrm{KNN}$, which is a machine learning algorithm, to rate a place/building for COVID-19 risk. We choose this algorithm to show the usability of machine learning in this scenario and compare it with a trust management algorithm. The results show the usability of machine learning algorithms to mitigate COVID-19. The block diagram demonstrating the the basic idea of this research is shown in Figure 1.

This article is significantly different to others already published as follows:

- Ullah et al. [11] presented various secure data collection mechanisms using fog computing in the healthcare sector. They, however, did not discuss the IoT use case of LPWAN as a connectivity option for these applications.

- Qadri et al. [12] presented a survey article that discusses emerging IoT healthcare technology system in general, but they did not focus on LPWAN as communication technology.

- Olatinwo et al. [13] discussed LPWAN technologies in wireless body area networks, but they did not discuss the advantage of machine learning in these applications. 


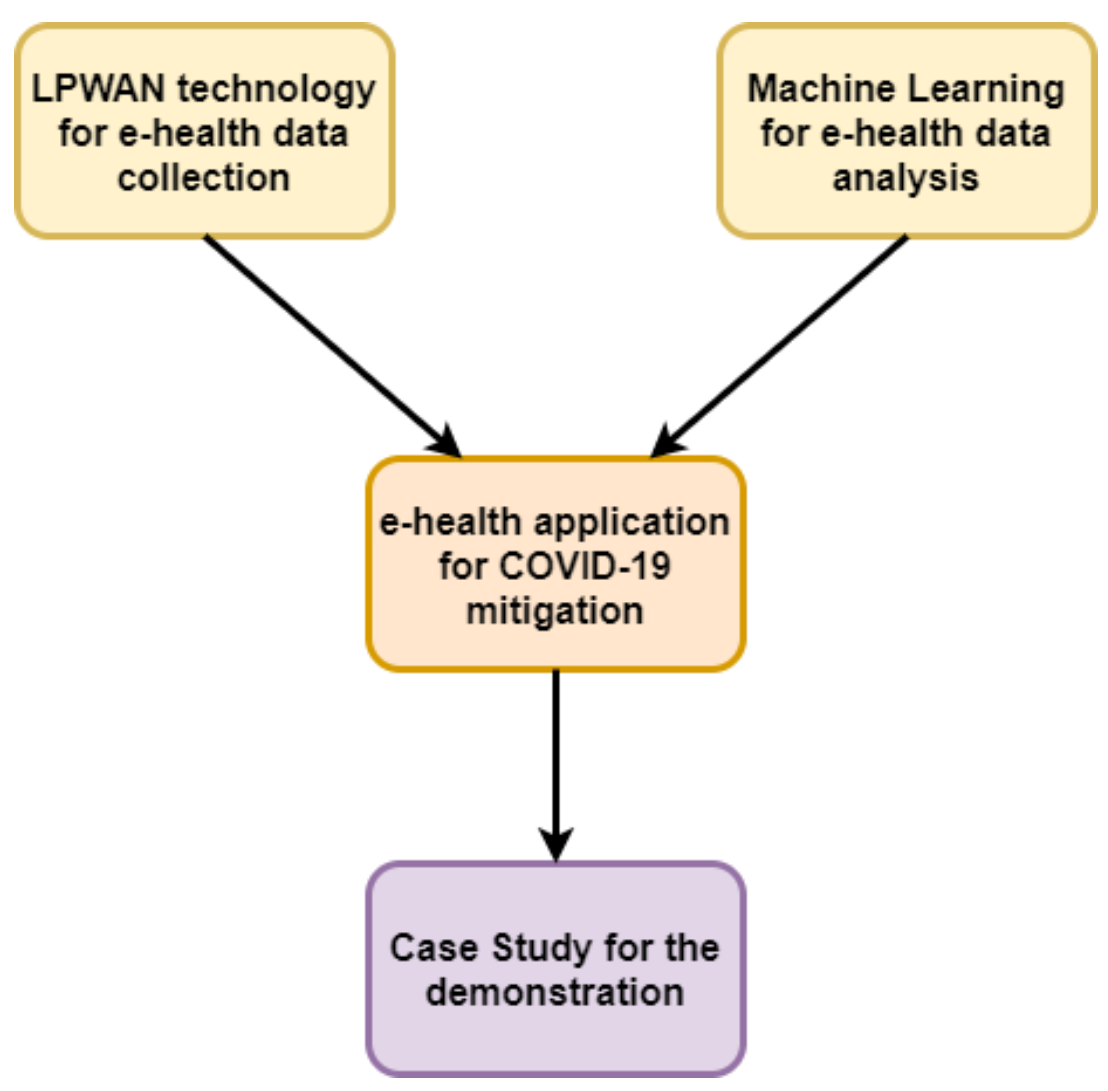

Figure 1. Block diagram of our research methodology.

The article is structured as follows. First, we sketch basic introduction to IoT and LPWAN in Section 2, while Section 3 discusses the e-Health applications using LPWAN technology. Thereafter, in Section 4, we give an introduction to machine learning and discuss the machine learning applications in LPWAN-based IoT healthcare applications and services for COVID-19 mitigation. We present a case study in Section 5 for the COVID19 pandemic using machine learning and trust development metrics. This is followed by a general discussion on the role of LPWAN-based systems during COVID-19 and the perspective work in Section 6. Finally, we conclude the article in Section 7.

\section{Internet of Things (IoT) and Low Power Wide Area Networks (LPWAN)}

In this section, we describe the role of IoT and LPWAN in automating our lives. These technologies and applications have revolutionized the way in which we can think of various application. LPWAN is a technology which is the basis for numerous emerging IoT applications. Below, we describe these topics in detail.

\subsection{IoT}

The future of computing is rapidly changing, and it is already out of the conventional desktop computer [14]. Already, we have an overwhelming number of devices which are surpassing the number of laptops and conventional desktop computers. Hence, Internet of Things (IoT) is becoming a new domain which is attracting huge amount of attention in the context of communication. In this domain, objects refer to small devices having limited processing and energy resources, and they can communicate with surrounding objects. Hence, communication and information is being shared around us in an invisible manner, and these objects are found around us in a pervasive manner. Many devices are part of the IoT: cell phones, sensors, Radio Frequency Identification (RFID), etc. These IoT objects will cooperate in a distributed manner to realize a common target [15]. IoT has its own properties, but it also shares similarities with other fields within computer sciences. Further, IoT devices combine various technologies in the domain of sensors, communication, 
actuators, cloud, and storing modules. Due to its powerful features, it is declared as one of the cutting-edge technologies by the US National Intelligence Council [16].

In the context of IoT, things can be defined as an entity that can record some activity and transfer the information to a central server. These things are identified using numbered addresses. They are an important part of the IoT as they are responsible for doing virtually everything in the network starting from monitoring and sensing to communication. These IoT devices would become an integral part of the Internet in the future, as standards have started to adopt these devices for the future.

However, there are a few definitions of the IoT which are proposed by some researchers:

Definition 1. 'Internet of Things (IOT) represents the next step towards the digitization of our society and economy, where objects and people are interconnected through communication networks and report about their status and/or the surrounding environment [17].'

Definition 2. 'A global infrastructure for the information society, enabling advanced services by interconnecting (physical and virtual) things based on existing and evolving interoperable information and communication technologies [18].'

Definition 3. 'The Internet of Things allows people and things to be connected Anytime, Anyplace, with Anything and Anyone, ideally using Any path/network and Any service [19].'

\subsubsection{Characteristics of IoT}

The IoT architecture combines features from the sensor networks, RFIDs, and other identifiable things to realize a dynamic network. Some of the important characteristics of IoT devices are listed below [20]:

- IoT devices consist of objects/things having real world devices which have the ability to identify each other.

- These devices can share information with each other using communication infrastructure.

- IoT devices may have sensors which can gather physical information, such as temperature, pressure, etc.

- These things can collaborate with each other to perform necessary steps.

- The IoT devices can communicate with any other device in the world using the Internet connectivity.

\subsubsection{Vision and Technology}

Due to advancements in technology, the processing devices are becoming versatile and accessible owing to better communication and processing features. The interconnectivity between these devices can benefit from these features and implement seamless applications. However, there is a need for unique identification of the things, such as public IP address. A single object in the IoT may have multiple sensors, which are individually addressable. Thus, large-scale IoT deployments need a global mechanism for addressing these objects. Further, this IoT architecture should be able to analyze information that is received from different sources. Thus, there are multiple dimensions of the IoT technology, including mobility, topology, network size, and heterogeneity, which need to be considered. The IoT network will dynamically evolve due to continuous joining and exiting of the things. Hence, these are some points which need to be considered before IoT network deployment. There are multiple connectivity options for IoT applications. Here, we consider LPWAN, which is an evolving connectivity option for IoT-based healthcare services [21]. The next section gives an overview of LPWAN technology. 


\subsection{Low Power Wide Area Networks (LPWAN)}

Different wireless technologies such as IEEE 802.11 (WLANs), IEEE 802.15.2 (Bluetooth), and IEEE 802.15.4 (ZigBee, LR-WPANs) are used in the sensor based applications. IEEE 802.11 and IEEE 802.15.2 were designed for the networks requiring high speed data transfer, while IEEE 802.15.4 was designed for low speed data communication. On the other hand, 2G-, 3G-, and 4G-based cellular networks were designed targeting data and multimedia (voice and video) communication having large coverage area.

Therefore, these wireless cellular networks are not designed while keeping in view the metrics of sensor-based applications. Hence, low power wide area network (LPWAN) has evolved, which is a new paradigm of the IoT network in order to support these requirements. LPWAN comprises multiple communication protocols for networks with large coverage areas and battery life, but having small data transmission rates [22]. For IoT and M2M, LPWAN technology has extensive capacity to support numerous applications involving constrained devices. It expects to have a price in the $\$ 3-7$ range, with packet sizes ranging $10-1000$ bytes and transmission data rates up to $200 \mathrm{kbps}$. The battery life should exceed 10 years, which can support more than 100k devices with coverage from 2 to $20 \mathrm{~km}[2,4,23]$.

In this section, we detail emerging LPWAN proprietary technologies and their features below. It includes a discussion of Sigfox, LoRa, Ingenu, and Telensa. These technologies provide their solutions in the the industrial, scientific, and medical radio (ISM) band.

\subsubsection{Sigfox}

Sigfox [23] is a proprietary solution for the IoT end-to-end connectivity. Sigfox Network Operators (SNOs) deploy their base stations around the globe for providing connectivity to the servers using IP-based networks. The end devices communicate with the base stations using the Binary Phase Shift Keying (BPSK) modulation scheme in sub-GHz ISM band. This reduces the noise levels, which results in long communication range. However, the data rate is also reduced and it can send up to $100 \mathrm{bps}$. This also decreases the application use cases which can consider this technology. The Sigfox allows uplink communications to 140 transmissions comprising 12-byte payload and downlink to four 8-byte messages per day and per device. Because of the same network provider, there is no roaming for a connected device if it changes its location [4].

\subsubsection{LoRa}

LoRa [4] is a proprietary technology that uses Chrip Spread Spectrum (CSS) modulation in sub-GHz ISM band, which spreads the signal over a wide frequency range. This helps in integrating the anti-jamming characteristic in this technology. Furthermore, the parameters at the physical layer can be modified to achieve a data rate from 0.3 to $50 \mathrm{kbps}$. This technology has better performance if a line of sight path is available; however, in the case of non-line of sight communication, its range is significantly reduced [24,25]. LoRa also supports the deployment of personal LoRa base station for network extension [23].

\subsubsection{Ingenu}

Unlike other LPWAN technologies, Ingenu supports communication in $2.4 \mathrm{GHz}$ ISM band; therefore, it does not face strict duty cycle restrictions [23]. It uses Random Phase Multiple Access (RPMA) proprietary technology, which is a variation of Code Division Multiple Access (CDMA) technique. As far as the data range and data rate are concerned, Ingenu has better performance that the other LPWAN technologies. Ingenu is dominating the task of standardizing the specifications of IEEE $802.15 .4 \mathrm{k}$ and is making RPMA technology compliant to this IEEE standard [4].

\subsubsection{Telensa}

Telensa is a networking company which provides LPWAN-based end-to-end connectivity [23]. Most of its applications are in the smart lightning network for the urban 
environment. Its physical layer uses a proprietary solution in sub-GHz ISM band, having a data rate of 62.5 and 500 bps for uplink and downlink, respectively. Thus far, they do not allow external users to use their network, but they are involved in standardizing their technology [4].

\section{3. e-Health Applications in LPWAN}

LPWAN is an effort of combining low power consumption with long-range wireless connectivity. In the recent past, several articles have been published to look into the e-Health applications by utilizing the 5G-based networks and LPWAN. The strategic requirements for the use of mobile technology in the health sector was sketched by [26], while [27] discusses the results of public assessment and proposed to use m-Health for improving the healthcare sector. Some other articles [28,29] explain the specifications and requirements of $5 \mathrm{G}$ technologies in the context of the healthcare sector. As per the study published by the European Commission [30], the global m-Health market would grow to 17.8 billion euros by 2017. Hence, there is strong evidence for the use of 5G- and LPWAN-based IoT networks in e-Health and $\mathrm{m}$-Health sector. An example LPWAN-based IoT application for e-health sector is shown in Figure 2.

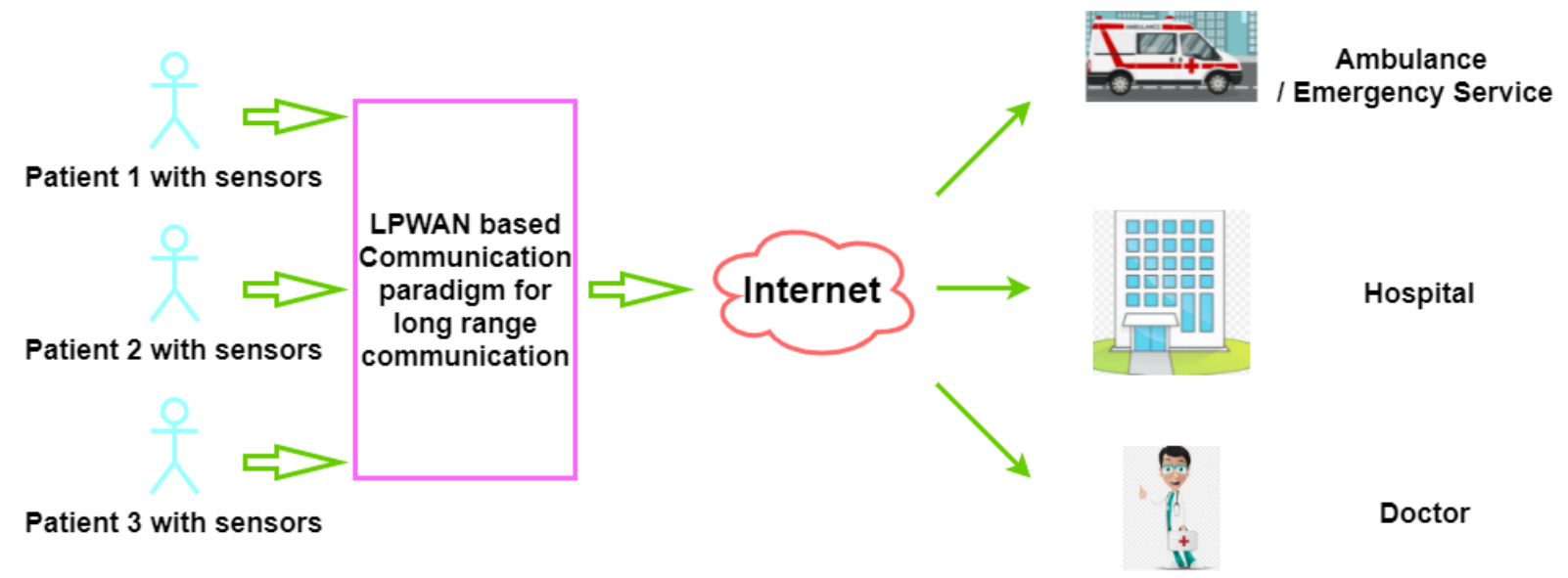

Figure 2. A conceptual LPWAN-based e-health application.

Many recent projects consider the e-Health concept. The estimated number of asthma patients was 334 million in 2014 [31], which may rise in coming years. For around 592 million diabetic patients, Ondou aims to provide electronic healthcare services [32]. Due to the characteristics of these diseases, the e-health services might require more than 1 billion LPWAN connections. These devices will help in managing the health needs of the patients, resulting in reduced hospitalization costs. Hence, more medical care can be provided to these chronic patients at home using the Internet and LPWAN technology.

In the following section, we discuss the LPWAN-based e-health application requirements.

\subsection{LPWAN-Based e-Health Application Requirements}

The main difference between Wireless Wide Area Networks (WWANs) and Wireless Local Area Networks (WLANs) is that WWAN targets a larger area in comparison with WLAN. The application requirements, such as traffic requirements, scalability, energy efficiency, coverage, location identification, security features, cost, and hardware features are different for both networks. The cellular data services such as $3 \mathrm{G}$ and $4 \mathrm{G}$ are designed for high data transfer over tens of kilometers in mobile devices. LPWANs, on the other hand, are designed for long-range data communication with low energy consumption, reduced cost, and low bit rate for M2M and IoT applications. Hence, it is a major component of any future IoT applications that require long transmission range. Many IoT-based ehealthcare services can be realized using LPWAN technology. The details are listed in 
the forthcoming sections. Here, we discuss the requirements of LPWAN-based e-health application requirements in detail below.

\subsubsection{Traffic Requirements and Mobility}

Several sensors can be deployed on an LPWAN. Other than their network traffic, LPWAN may also have traffic generated by other devices. The traffic attributes for LPWAN may vary as well in terms of real time data delivery and energy efficiency. Some applications may be delay tolerant and others delay intolerant. Similarly, in an LPWAN-based e-health application, some applications such as usual remote monitoring of patients may be delay tolerant. However, in the case of an emergency, the packets should be prioritized and should reach the concerned doctor in a timely manner. Similarly, some of the applications should also require the provision of mobile device in an LPWAN. Thus, there is a need to handle various traffic classes and mobility in LPWANs for e-health applications. Although the current LPWAN technologies do not offer priority mechanism for packet transmission, this feature might be added to existing technologies. This can be achieved by increasing the number of base stations for LPWAN technology to handle various traffic classes.

\subsubsection{Scalibility}

Another important feature of LPWAN in the healthcare sector is to allow a large number of devices to have low data rates. For example, if the healthcare agency of a country wants to automate the process using LPWAN technology, then a lot of devices would be needed and scalability is a major issue. Scalability is the property of a network which can grow from a small number of devices to a large number. However, this should not affect the network data transmission ability [33]. There is an important role of gateways in the scalability issue, as most LWPAN devices connected to provide e-health services are low cost, having restricted processing abilities. Here, multi-channel and multi-antenna techniques can be used to improve scalability in these type of networks [2]. The multichannel and multi-antenna techniques reduce the interference and increase the network performance [34]. Hence, we conclude that this is a very important design factor for LPWAN-based e-health services.

\subsubsection{Energy Efficiency}

One of the main properties of LPWAN-based e-health applications is the unavailability to recharge the devices periodically. Furthermore, the cost of battery should be kept low. Hence, there is a need to use LPWAN devices in a low duty cycle mode and they should be kept in sleep mode whenever possible. This will help in enhancing the battery lifetime, and it is expected to last at least ten years. However, in an emergency event, the duty cycle should be modified to provide essential healthcare service to the patient. There is a need to have further research in this domain so that the batteries having long lifetime should be designed to effectively realize these e-health applications.

\subsubsection{Coverage}

As per Raza et al. [4], the coverage range for LPWAN should be up to 10-40 km in rural environment and $1-5 \mathrm{~km}$ in urban areas. For most e-health applications, this is an important design parameter. Since LPWAN technologies may have disparity in communication range, it must be considered before choosing a particular technology for an e-health application. As the devices need to be deployed in indoors and underground locations for remote monitoring of the patients. Hence, it is important to have a better coverage as some of the patients can be in critical stages. If an LPWAN technology is unable to provide the required coverage, then it can have negative consequences on patient's health.

One choice is to use low modulation rates at the physical layer, but it increases the energy required per bit. However, it will help the receiver in correct detection of data without the need for re-transmission. Anther choice is to consider the data rate for a particular e-health application. If we need a higher data rate, then we can compromise on 
the the transmission range, and a dense deployment of LPWAN base stations is required. On the contrary, for e-health applications requiring lower data rate, the transmission range can be reduced. This will lead to a sparse deployment of the LPWAN base stations. Hence, the coverage range is an important parameter for the deployment of a particular e-health application.

\subsubsection{Location Identification}

The location gathering of LPWAN devices is an important aspect as patients can change their location frequently. If the patient is in need of critical care, then his/her location should be known to the healthcare provider. Then, the required services may be provided to the patient. Thus, the devices may be integrated with a global positioning system (GPS) device or they should use smart localization algorithms to know the current location of an LPWAN device and the patient.

\subsubsection{Security and Privacy}

The security and privacy is an important feature of LPWAN devices because of their simplicity. In order to avoid any malicious user to misuse the healthcare system, the need for authorization, authentication, data security, and confidentiality needs to be supported. These security services should be able to stop major Denial of Service (DoS) attacks against these devices. Otherwise, a malicious user can penetrate the system, and it can cost the health of the patients.

\subsubsection{Cost Effectiveness}

As discussed above, LPWAN devices and their operation cost should be low without compromising at the communication range. Furthermore, software upgrading should also be supported in these devices. Both of these points would enable a cheaper deployment and operational cost for providing healthcare services. This would be beneficial for both the service provider and the patient.

\subsubsection{Device and Software Complexity}

LPWAN devices deployed in a healthcare system would need lower operation cost with a long coverage range. Furthermore, the software should not require a lot of processing resources in general, as this would increase the power consumption of the device. This would simplify the network deployment task and would help in reducing the operational cost of the network.

\section{Machine Learning for e-Health}

In this section, we first give an overview of machine learning techniques and algorithms. Thereafter, various e-health applications are discussed that may use machine learning for their realization. Then, a brief overview of COVID-19 is presented. Finally, we describe e-health services for mitigating COVID-19 spread using machine learning and e-Health applications.

\subsection{Machine Learning}

Machine learning is a part of artificial intelligence and its objective is to comprehend the data and generate a model which can be interpreted by human beings [35]. It is one domain of computer science, but there is a major difference, that is, traditional computer science has programs for algorithm solving. However, machine learning algorithms fit the pattern of data into a mathematical model using statistical analysis. Thus, it automates the decision making process by building a mathematical model and helps in analyzing the situation based on data inputs.

Many technologies benefit from machine learning. Facial recognition may be used by the social media websites for tagging the users in photos by using machine learning algorithms. Search and recommendation engines can suggest user various contents to 
watch by the help of machine learning. There is another advancement in the field of self-driving cars which use machine learning for effective decision making.

In this section, we look into machine learning methods including supervised and unsupervised learning, and other algorithmic approaches used in machine learning.

\subsubsection{Machine Learning Methods}

Broadly speaking, machine learning is classified into four categories. These are supervised, unsupervised, semi-supervised and reinforcement learning. These techniques depend on the type of learning mechanism for developing a model.

\section{Supervised Learning}

Supervised learning [36] trains algorithms based on labeled data. The dataset used in model construction is referred to as training data and there are labels associated with these data. In general, the aim of supervised learning is to identify the pattern within given datasets. The algorithm learns by comparing the actual output with the outputs obtained from the model to locate errors and update the model accordingly. For example, we may label part of an image of the ocean as fish and the rest as water. After training on these data, a supervised learning algorithm should be able to identify fish and water in other images. Another example is prediction of future events based on historical data or filtering out spam emails from received emails.

\section{Semi-Supervised Learning}

In the case of partial knowledge such as incomplete labels or missing labels, semisupervised learning techniques [37] are effective. Generally, this technique utilizes less labeled data and more unlabeled data for model training. Hence, it combines the features of supervised and unsupervised learning techniques, by using labeled as well as unlabeled training data. In order to understand semi-supervised learning, let us take an example of cluster analysis. This method partitions a dataset into similar groups such that each group is different from another. Normally, clustering is done using unsupervised learning; however, in some cases where some labels or information about data relationship is unknown, semi-supervised learning methods are effective.

\section{Unsupervised Learning}

Unsupervised learning algorithm [38] is not provided labeled data; rather the algorithm itself decide about the learning boundaries. The input data for unsupervised learning are unlabeled, and the learning algorithm finds common features in the dataset. This approach is most suited for clustering problems such as outlier detection. Most available data are unlabeled; therefore, this type of learning mechanisms is more valuable. Hence, one of the main objectives of the unsupervised learning is to discover hidden patterns in a dataset. One example of unsupervised learning is anomaly detection in the cyber security systems for detecting fraudulent activities. Another example is the purchase data of customers, which can be used to launch different types of marketing campaigns for a certain product.

\section{Reinforcement Learning}

Reinforcement learning (RL) [39] is an iterative process based on an agent for decisionmaking problems. The idea here is to use an agent for interacting with the external world by utilizing the environment and knowledge. Training data in RL are based on action and rewards. Agents learn from the environment to implement algorithms for maximizing the reward. Generally, there is an important relationship among the problem, learning paradigms, and the training dataset. Due to the lack of knowledge regarding the training data, it might be possible that supervised learning may not be employed while other learning techniques might work. 


\subsubsection{Machine Learning Algorithms}

The machine learning approaches are based on computational statistics, which are based on the concept of correlation and regression. The approaches to apply machine learning are continuously developing, and it is a hot area of research. Here, we discuss various approaches for applying machine learning algorithms.

\section{k-Nearest Neighbor (KNN)}

The k-nearest neighbor algorithm [40] is an example of supervised learning, and it is used for pattern recognition, classification, and regression problems.

In this method, the input consists of $k$ closest training examples, hence the name. To better explain the problem, let us consider an example. In Figure 3, there are diamonds and star objects, which belong to different classes. If we add a heart to the space, then the machine learning algorithm will classify it to a certain class. Here, we take $k=3$ and the algorithm will find the three nearest neighbors to make a decision. In our example, the algorithm will make heart part of the star class.

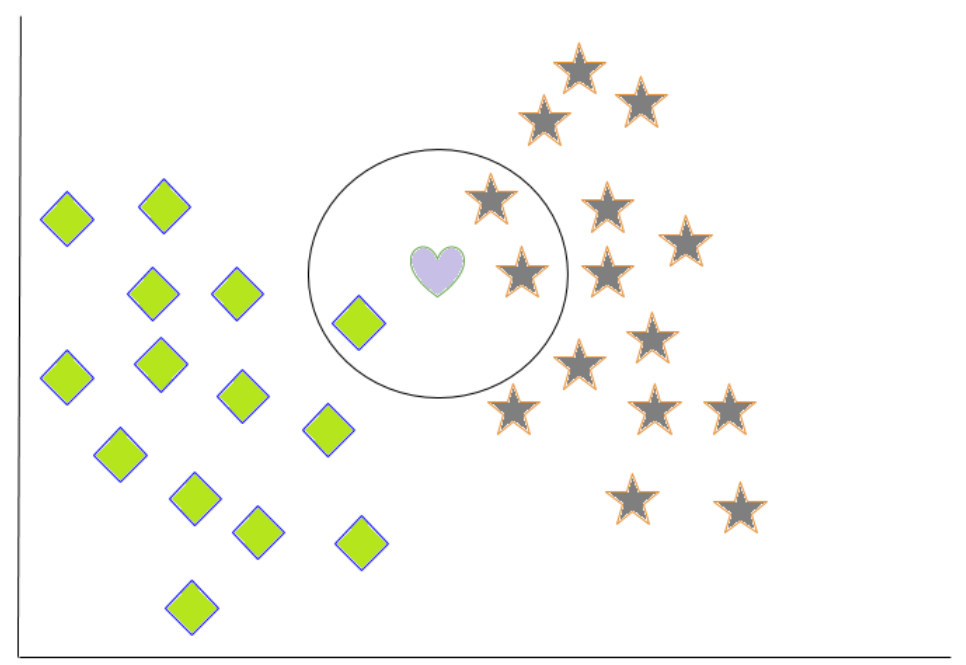

Figure 3. KNN example.

The KNN algorithm uses Euclidean distance to compute its $k$ closest neighbors using the difference between its feature vector and that of the neighbor. The squared value of the difference is added together to get the distance as per the equation below [41]:

$$
\begin{aligned}
\text { Distance }^{2}= & \left(\text { feature }_{1, \text { object }}-\text { feature }_{1, \text { neighbor }}\right)^{2}+ \\
& \left(\text { feature }_{2, \text { object }}-\text { feature }_{2, \text { neighbor }}\right)^{2}+ \\
\ldots+ & \left(\text { feature }_{n, \text { object }}-\text { feature }_{n, \text { neighbor }}\right)^{2}
\end{aligned}
$$

A voting-based mechanism is used to classify the input vector into corresponding category. This is a useful mechanism even if the training data is relatively small. Therefore, $\mathrm{KNN}$ is used in the case study that we develop in this article.

\section{Decision Tree Learning}

The decision tree [42] is an example for supervised learning, and it is used as a predictive model in machine learning. It predicts the value of a target by considering the input variables. In this model, branches of the tree represent observations and leaves represent conclusions about the data target. The quality of the outcome depends on the criterion known as entropy, which has to be minimized and helps in judging the final outcome [43]. For example, someone wants to know if he should go fishing based on weather and pressure conditions. In decision tree-based learning, we have to find an 
appropriate leaf node after a sorting process for a particular example. Based on the weather conditions of a day, the tree classifies whether it is suitable to go fishing. Hence, a particular decision can be made using such a tree.

Principal Component Analysis (PCA)

PCA [44] was invented by Karl Pearson in 1901, and, in this process, we first compute the principal components in a dataset. It is a part of the unsupervised learning algorithm stream. These components are used to perform a change of basis on the data, by considering first a few principal components, hence the name. PCA simplifies the complexity in the data, by keeping the data trends. Concretely, this algorithm works by defining a new coordinate system using the data variance. The largest variance of data helps in identifying the first axis, the second largest data variance along the orthogonal direction to the first axis identifies the second axis, and so on. This mechanism continues until all the axes are located [43]. That is how the unsupervised learning mechanism of PCA works and helps in processing the unlabeled data.

\section{Support Vector Machine (SVM)}

SVM [45] is a supervised learning model used in machine learning, and it is used for regression and classification analysis. A labeled dataset is passed to the SVM model, and it is able to categorize further data. It helps in classification of data into two groups by creating a decision boundary in space for separating the two classes. The decision boundary is selected such that the gap between data points in the two classes is maximized. The decision boundary can be separated using linear as well as non-linear kernels [43]. Thus, it can be used to classify unlabeled data in healthcare for realizing interesting applications.

\section{Artificial Neural Network (ANN)}

ANN [46] is an example of supervised learning algorithm, and it is designed to copy the brain functionality. It is a layered structure, which performs linear and nonlinear transformation on the input data and develops the classification rules. It has an input layer to receive the data, inner layer(s) for processing the input data, and an outer layer for generating the results. In the case the output is incorrect, the output can be fed back to the inner layer for further processing until acceptable results are obtained [41]. It is using implemented in software, but sometimes it is fabricated in hardware.

\subsection{Machine Learning in LPWAN-Based IoT Healthcare Applications}

Many healthcare applications can use LPWAN and machine learning. In this context, various healthcare devices available on the market are discussed. These devices may lead to an innovative development of healthcare solutions using machine learning. In this section, we discuss various IoT-based healthcare applications which uses machine learning and can be used by various healthcare services.

\subsubsection{Blood Glucose Testing}

Blood glucose monitoring [47] is vital for diabetic patients, as they have high glucose levels over an extended period of time. This monitoring indicates the pattern of glucose level present in an individual's blood, which helps in deciding meal plans, medications, and physical activities. LPWAN-based IoT applications used with machine learning would be beneficial for deciding these plans based on the past history of a patient. LPWAN devices would monitor and record the blood glucose level periodically, and the data would be used by a machine learning application to decide about the patient's daily plan. An example of IoT-based noninvasive glucose monitoring is proposed in [48], where healthcare providers are given access to the patient's data through IPv6 connectivity. Another IoT-based medical data gathering system is explained in [49], which detects the glucose level of a patient. 


\subsubsection{Electrocardiogram (ECG)}

ECG [50] is the heart activity which is recorded by electrocardiography for determining heart rhythm, multifaceted arrhythmia, and the myocardial ischemia [51]. LPWAN devices can be used to capture these data for obtaining maximum information, which can be used for extensive analysis [52]. Further, these data can be exploited by the machine learning for early detection of heart-related diseases. ECG monitoring using IoT is described in detail in [53-55].

\subsubsection{Blood Pressure (BP) Monitoring}

BP monitoring [56] is an important part of early detection of various heart diseases. Therefore, its monitoring using LPWAN is vital for many patients. In [57], an architecture is proposed for BP monitoring using IoT and the smartphones. Another scenario is discussed in [58], which presents a communication mechanism between a remote health office and the central medical center for constant BP monitoring. Based on the collected data, machine learning can be used to make a model for prediction of a possible illness.

\subsubsection{Temperature Monitoring}

The use of LPWAN devices coupled with machine learning would help in realizing such an IoT application. One of the critical vital signs is the body temperature [59], which needs regular monitoring for critically ill patients [60]. TelosB mote is used in conjunction with a temperature sensor in [48] for monitoring body temperature periodically. Another example is given in [61], which employs a home gateway on top of the IoT network, which detects the body temperature and transmits using infrared sensors. In [62], another similar system is presented, which uses the RFID module and a module for body temperature monitoring.

\subsubsection{Blood Oxygen Saturation Monitoring}

Oxygen saturation monitoring [63] can be carried out by pulse oximetry. In order to realize healthcare application, pulse oximetry can be integrated with LPWAN. The potential for using this technique is detailed in [64]. A platform for implementing the techniques using Bluetooth is described in [54]. Similarly, Larson et al. [65] presented a remote monitoring system using a low power pulse oximeter over an IoT network. A telemedicine application using pulse oximeter is detailed in [66]. The data obtained from these applications can be utilized by a machine learning software tool to know about any possible health issues in the monitored patient.

\subsubsection{Rehabilitation Management}

One vital branch of medicine is rehabilitation management [67] for restoring functional ability of a patient having some physical disability. In the case of shortage of experts and aging population, this field can be well supported by LPWAN. LPWAN can be used to gather information related to the person's disabilities and his age, and a schedule for rehabilitation can be planned. This plan can be obtained from a machine learning application having data of the past patients. Another example is given in [68], which provides an ontology-based automated technique for a IoT-based rehabilitation system offering realtime information exchanges. Another example of remote consultation for rehabilitation is explained in [69]. The reader is referred to other examples presented by Lin [70], Guangnan and Penghui [71], Yue-Hong et al. [72], and Liang et al. [73]. All of these systems can help to gather patient data for rehabilitation using an IoT network, which can be used to make a rehabilitation plan using a machine learning application.

\subsubsection{Medication Management}

The noncompliance of medicine management [74] results in a serious problem to the community health, hence it is an issue which needs to be addressed. LPWAN provides an innovative mechanism for managing this problem. An example is given in [75], which provides an IoT-based intelligent packaging solution with controlled sealing employing 
wireless communication. Another relevant medication management system using RFID is detailed in [76], which describes a prototype implementation for medication control system. Past data gathered using the IoT network can be used to have better control on the future movement of medication using a machine learning application.

\subsubsection{Wheelchair Management}

There is a need to work on wheelchair automation [77] for handicapped patients, and LPWAN can help in the development of such a chair. In [78], a wheelchair healthcare system based on IoT technology is described. This design integrates WBAN technology with the IoT system. Another example is given in [79], which uses peer-to-peer and IoT systems for chair vibration control. The wheelchair movement data can be used by a machine learning application to derive behavior of the wheelchair users. This behavior prediction would help in optimizing the wheelchair usage for the other users.

\subsubsection{Smartphone-Based Healthcare Solutions}

Smartphones have become a common electronic gadget which is carried by almost everybody these days. There are many interesting hardware and software features which make it an ideal candidate for a healthcare device [80]. In [81], various healthcare apps are discussed for advancing the healthcare services. Similarly, White et al. [82] discussed image analysis algorithms that can be used in a healthcare application for non contact measurements. Another survey [83] describes various smartphone apps that are available for the healthcare system. There are some smartphone-based healthcare accessories, such as Fitbit Flex, which help individuals achieve better fitness levels. These smartphones can be integrated with backend systems for collecting useful information necessary for a machine learning system.

\subsubsection{Other Areas of Interest}

There are many healthcare areas where the integration of LPWAN would help in better realization of these services. There are many new portable devices which can check various signs of a patient, including peak expiatory flow, eye pain, cancer treatment, skin infection, and hemoglobin detection [84]. The data obtained from these devices through an LPWAN would help a machine learning application to build a model for future applications.

\subsection{COVID-19}

The new coronavirus (SARS-CoV-2) has become a raging pandemic due to its high death rate and lack of medical treatment. It has spread across 222 countries with a death toll rising up to 3.44 million [85]. After entering through the human respiratory system, it causes severe conditions similar to pneumonia. The symptoms of the disease are so common that it is difficult to diagnose. Moreover, the limited availability of testing kits made the problem further grave. To mitigate the issue, researchers around the world are investigating novel mechanisms and technology for rapid and effective diagnosis and control the spread of virus. Although, a lot of work is done for finding medication, so far social distancing, lockdowns, and other preventive measures are the only effective solution. The worst part of all these measure is the effect on economic and psychological conditions of the people.

Recently, healthcare providers and researchers around the world focus on machine learning and artificial intelligence to increase the speed and processing power for performing several healthcare-related tasks [86]. Therefore, a health clinical system based on artificial intelligence and machine learning can address the challenges of COVID-19 pandemic. In the healthcare industry, artificial intelligence cannot replace human interaction, but it can provide effective decision support for clinicians for modeling the data and predicting different outcomes [87]. The e-Health applications that are explained in the previous subsection can be used for realizing various healthcare services for mitigating the spread of COVID-19. These services are explained in the next subsection. 


\subsection{Machine Learning in LPWAN/IoT Based Healthcare Services for COVID-19 Pandemic}

Recently, researchers have started to focus on various use cases of IoT applications using LPWAN. Especially, they are interested in healthcare sector, however, these articles do not discuss the role of machine learning by using LPWAN technology. Furthermore, there is a potential of LPWAN-based IoT applications which can be used to mitigate COVID-19. As discussed in the Introduction, this article explores the usage of machine learning in the context of a healthcare IoT application which uses LPWAN. Table 1 gives a comparison of IoT-based healthcare articles, which shows that there is potential to discuss LPWAN-based IoT healthcare applications for COVID-19 using machine learning.

Table 1. Comparative analysis of related surveys for healthcare applications.

\begin{tabular}{cccccc}
\hline Ref. & $\begin{array}{c}\text { Short Range } \\
\text { Communication } \\
\text { Technology }\end{array}$ & $\begin{array}{c}\text { LPWAN for } \\
\text { Communication in } \\
\text { Healthcare Applications }\end{array}$ & $\begin{array}{c}\text { Machine Learning in } \\
\text { LPWAN Based } \\
\text { Healthcare Applications }\end{array}$ & $\begin{array}{c}\text { Security in } \\
\text { Healthcare } \\
\text { Applications }\end{array}$ & $\begin{array}{c}\text { LPWAN Based } \\
\text { IoT Applications } \\
\text { for COVID-19 }\end{array}$ \\
\hline$[11]$ & $\checkmark$ & $x$ & $x$ & $\checkmark$ & $x$ \\
{$[12]$} & $x$ & $\checkmark$ & $x$ & $x$ & $x$ \\
{$[13]$} & $x$ & $\checkmark$ & $x$ & $x$ & $x$ \\
{$[88]$} & $x$ & $\checkmark$ & $x$ & $x$ & $x$ \\
{$[89]$} & $x$ & $\checkmark$ & $x$ & $x$ & $x$ \\
{$[90]$} & $\checkmark$ & $x$ & $x$ & $x$ & $x$ \\
{$[8]$} & $\checkmark$ & $x$ & $x$ & $\checkmark$ & $x$ \\
{$[91]$} & $\checkmark$ & $x$ & $x$ & $\checkmark$ & $x$ \\
{$[92]$} & $\checkmark$ & $x$ & $x$ & $x$ & $\checkmark$ \\
{$[93]$} & $x$ & $x$ & $x$ & $x$ & $x$ \\
{$[94]$} & $x$ & $x$ & $x$ & & \\
\hline
\end{tabular}

Several healthcare services for epidemic diseases can be provided by integration of LPWAN into the system. However, standard IoT services are defined for the healthcare system, as the world has not witnessed such a situation before. Various solutions can be offered by machine learning-based techniques. This section explains existing services which can be used to detect the presence of infectious diseases in humans and is inspired from Islam et al. [90]. The protocols and services for LPWAN might require modification to control diseases. This enables fast and secure discovery of devices for providing these services. In the scenario of COVID-19, the importance of LPWAN-based medical services has received particular attention, as they may help in reducing the spread of any pandemic by maintaining a safe distance between the patient and other people. Some of the healthcare services which are useful in the time of a COVID-19 pandemic are drawn in Figure 4.

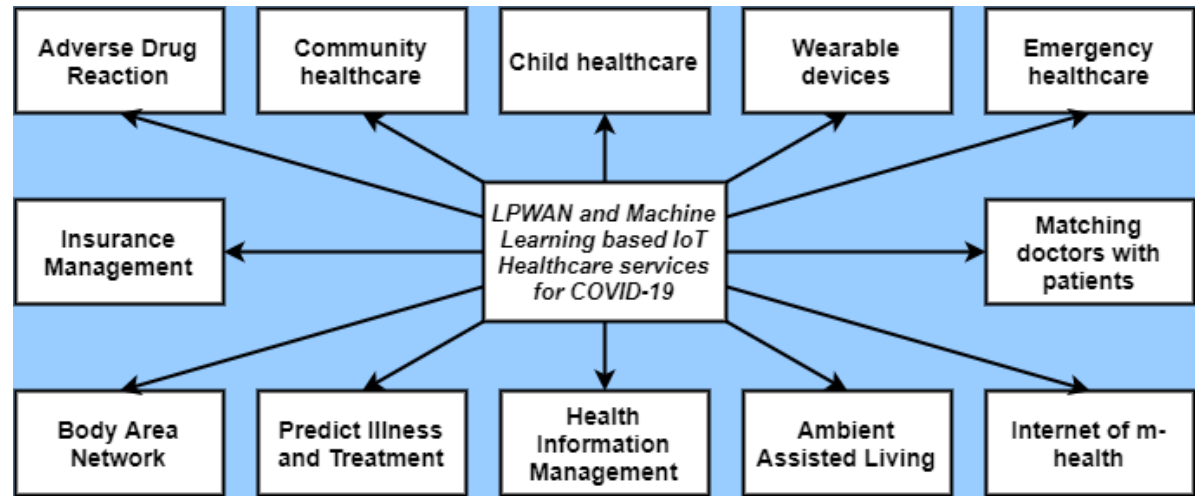

Figure 4. Healthcare services for LPWAN.

We discuss various types of LPWAN-based healthcare services for epidemic diseases in detail below. 


\subsubsection{Patient Data Monitoring (Body Area Network)}

In the context of epidemic diseases, it is not only important to keep the patient monitored, but it is also required to take care of healthcare personnel. Therefore, Body Are Network (BAN) [95] can provide a patient monitoring network that can save the paramedic staff from these diseases. BAN consists of different sensors that monitor vital signs of the patient. BAN is installed on the patient for monitoring vital signs. The contact between patient and healthcare professionals can be reduced in this way. In the case of an emergency, the emergency response can be initiated by the healthcare professionals. Further, in the case of epidemic diseases, the patient can be advised to stay at home in quarantine. The patient can be remotely monitored based on the readings obtained from BAN. In the case the patient is staying alone at home, he/she can be monitored remotely. For the case of an emergency, an ambulance can be dispatched to his/her residence. Based on the vital signs, the machine learning can be used to predict the state of patients, that is, whether they are cured or their situation is getting worst. In the case of a worst situation, the patient can be shifted to a hospital for better treatment.

\subsubsection{Predict Illness and Treatment}

Machine learning can be used to predict illness of a patient [96]. The data from past patients are used to develop such a model. This model gives us an idea about the condition of a patient, that is, whether the condition is serious or not. If the patient is predicted to have symptoms of virus, then the patient can be isolated earlier. This will help reduce the propagation of the disease. The probable patient is treated for better management of the disease.

\subsubsection{Health Information Management and Exchange of Health Information}

The machine learning can be used for better health management [97] in epidemic diseases cases. The data collected at every district of a country give useful insight into the spread of the disease. The government can take steps to control the spread of the disease by looking at those parameters. Some countries have introduced smart lockdowns, which are based on machine learning algorithms [98]. This helped in controlling the spread of the disease as well as keeping the economy active.

\subsubsection{Ambient Assisted Living}

The medical service which helps in aiding elderly and handicapped patients using machine learning is called Ambient Assisted Living (AAL) [99]. The main ambition of AAL is to increase the life of an elderly patient with minimum or no dependence in their residence providing security, ease, and comfort. The quick fix by AAL utility can be a source of giving freedom and authority to the old and dependent patients, elevating their self-belief by coming up with human-servant-like assistance in the time of any difficulty. Many researchers have considered an AAL constructed on top of IoT. A standard model architecture for labor saving technology, safety, authority, and transmission is suggested using IoT-based AAL in [100]. The primary mechanisms for the application of this architecture are 6LoWPAN, which is employed for active communication protocol, whereas Radio Frequency Identification (RFID) and Near-Field Communication (NFC) are used as passive communication. AAL has been expanded by integrating data composed by therapeutic understanding to spot complication and hazards met by senior patients.

An AAL paradigm is discussed in [57], including how the primary AAL model can be realized using IoT. It has been debated that the application of AAL can be made easier by merging Keep-In-Touch (KIT) smart objects and closed-loop healthcare assistance. This consequent foundation can allow LPWAN to communicate between participants such as elderly patients, medical staff, doctors, caretakers, and relatives. The above-mentioned endeavors have inspired researchers to design protocols for creating KIT smart objects and closed-loop healthcare services workable via LPWAN.

In [101], a secure and flexible platform using IoT and cloud computing is described. This foundation discusses multiple features related with internetworking. The safe stream- 
ing, Quality of Service (QoS), and data storage and its practicality have been confirmed by deploying a health gateway employing IoT on a desktop-based implementation. The preceding articles discuss the requirement of AAL and its correlated technological assistance and bring forth an interesting system for innovatory AAL technologies [102]. Additionally, an IoT-based safe system for AAL-based medication control is explored in [103].

Based on the presented articles, we can use machine learning and LPWAN technology to provide medical services to elderly and handicapped patients in a pandemic situation. This can be done by analyzing the health of these patients and isolating them from the other population. This will not only provide better health services to these patients, but also AAL can indirectly slow the spread of a pandemic disease.

\subsubsection{Internet of $\mathrm{m}-\mathrm{Health}$}

Technology such as mobile computing, body medical sensors, and communication is used for facilitating medical management these days [104]. This concept is defined as $\mathrm{m}$-health in [105]. Theoretically, m-IoT acquaints an out of the box medical management integration model that links the 6LoWPAN with the progressing $4 \mathrm{G}$ networks for future Internet-based $\mathrm{m}$-health services. $\mathrm{m}$-IoT fundamentally symbolizes IoT for medicinal services. It is important to discuss those particular traits that are inherent to the international free movement of an engaging organization. This moves towards the design of m-IoT services. The usage of m-IoT for noninvasive sensing of the glucose-level and the m-IoT planning concerning its execution and the difficulties faced are discussed in [48]. Contextaware problems and $\mathrm{m}$-IoT ecosystems are two well-defined confronting matters in $\mathrm{m}$-IoT utilities [102]. A methodology for mobility based on sharing packets is initiated, but its low network power usage is not confirmed in [100].

In a pandemic situation, m-IoT would be able to provide vital medical services to isolated patients, without risking the health of a healthcare provider. m-IoT services would also be able to monitor the patients remotely. Hence, it can help in stopping the spread of the pandemic disease.

\subsubsection{Adverse Drug Reactions}

An adverse drug reaction (ADR) is defined as trauma caused by the use of a medication $[106,107]$. ADR can occur following the first time intake of a medicine, if it is used for a long period of time, or as a result of the composite of two or more medicines. As ADR is naturally not specific to the therapy for a certain ailment, there is a requirement to individually plan a well-defined common technical issues and their mechanisms, which are called ADR services. In [108], a proposal for an IoT-based ADR is given. In this proposal, the patient's workstation recognizes the medicine through barcodes or NFC-based devices. Through the use of pharmaceutical information system, the data are correlated to discern that the drug is in tune with the patient's health record for allergic medications. iMedPack has been designed as a fragment of iMedBox to discuss the ADR by utilization of RFID and Controlled Delamination Material (CDM) technologies [53].

In the case of a pandemic situation, ADV can help a patient by providing medicine based on its past drug reaction history. Thus, the need to travel to a healthcare facility is reduced after consulting the history. This will also help better control a pandemic disease.

\subsubsection{Community Healthcare}

The concept of community healthcare [109] is deployed with the help of a network which covers a local community. This may include a residential building, a hospital, or a rural commune. Various such networks can be integrated to realize such a community healthcare structure. In [84], a rural healthcare monitoring system using an IoT network is proposed, which includes a unique authorization and authentication system. Lei You et al. [110] described a community healthcare network by integrating multiple Wireless Body Area Networks (WBANs), which can be considered as a virtual hospital. Similarly, Weihua Wang et al. [111] explained a framework for obtaining patients' health 
records and suggesting remote medical advice. These community healthcare units can help in the time of a pandemic for better management and lesser spread of the virus.

\subsubsection{Child Health Information}

It is important to make awareness about the children's health for improving their emotional and mental needs [112]. This can be addressed by using IoT service termed as children health information (CHI). An interactive device explained in [113], helps in offering $\mathrm{CHI}$ based services to the children admitted in a hospital ward. The nutritional habits of the children can be improved using an IoT-based m-health service explained in [114]. In the time of a pandemic, these devices can be configured for providing better child healthcare services.

\subsubsection{Wearable Devices}

In [115], different sensors have been described that are used for providing healthcare services. These sensors can be used by an LPWAN for delivering these services. Many wearable devices can be produced using these sensors. The LPWAN architecture can be realized using these devices. However, these devices pose challenges due to their heterogeneous nature. Therefore, the integration of these devices has been tackled by various research works. For example, Castillejo et al. [116] developed a prototype system which can be accessed by smartphones and smartwatches. Further, Bazzani et al. [117] explained an IoT-based activity monitoring with the help of wearable devices. Lastly, Lopez et al. [118] explained the use of Bluetooth for the wearable devices and Ghazi et al. [119] discussed focal vibration therapy using wearable devices to provide neurophysiological benefits.

These devices are useful during a pandemic, as the vital signs of a patient can be monitored remotely. This will keep an isolation between patient and the rest of the world, which will decrease the spread of the virus.

\subsubsection{Emergency Healthcare}

In the case of a calamity, several healthcare tasks are involved [120]. These situations involve accidents, fire, etc. Emergency healthcare systems based on LPWAN and machine learning will greatly help in maintaining the service quality. Based on past experiences, the machine learning model will help in safely realizing the service. These emergency healthcare services might also be beneficial during a pandemic. Since these are based on LPWAN devices, a safe distance can be maintained between patients and healthcare providers to bring safety into the life of paramedic staff.

4.4.11. Help Insurers to Save Time and Money on Healthcare for People to Locate the Least Expensive Providers

Depending on the type of healthcare providers, it is important to locate the best service for a person [121]. For example, a young healthy person can choose a very low cost service provider to get maximum cost benefit. On the other hand, an elderly person needs more care. Hence, based on the age and medical history of a person, the best medical service can be chosen. This can be done with the help of machine learning applications which can guide a person.

In a pandemic situation, these applications would guide patients to select a hospital which best meets their budgetary and health requirements. This will help in better usage of healthcare resources.

\subsubsection{Use Machine Learning to Better Match Patients with Doctors}

The selection of a doctor is critical for a patient [121]. For example, if patients need specific care, then they need to choose a specific doctor to cater to their needs. Based on a machine learning application, the patient can choose the nearest doctor who is best for his symptoms. Thus, it will reduce the travel requirements of a patient to locate a specific doctor to cure his disease. This application can be useful in a pandemic disease for better care management. 


\subsubsection{Discussion Regarding Mapping a Service to Machine Learning Algorithm}

The suitability of a particular machine learning algorithm for a healthcare services during COVID-19 is listed in Table 2. This table describes the use of particular type of machine learning algorithm for providing healthcare services in COVID-19. Based on the past research, in our opinion, unsupervised learning should not be used for critical services having realtime deadlines such as illness prediction and treatment, AAL, matching doctors with patients, ADR, emergency healthcare, and mitigation of viral diseases. Furthermore, semi-supervised algorithms should not be considered in emergency situations, which include ADR, emergency healthcare, and mitigation of viral diseases. However, supervised learning may be deployed for any type of healthcare service, as mentioned above. This strategy is proposed because the lack of labeled data may have a negative impact on patient's health.

Table 2. Suitability of machine learning algorithms for healthcare service in COVID-19 mitigation.

\begin{tabular}{lccc}
\hline $\begin{array}{l}\text { Healthcare } \\
\text { Service }\end{array}$ & $\begin{array}{c}\text { Supervised } \\
\text { Learning }\end{array}$ & $\begin{array}{c}\text { Unsupervised } \\
\text { Learning }\end{array}$ & $\begin{array}{c}\text { Semi-Supervised } \\
\text { Learning }\end{array}$ \\
\hline Body Area Network & $\checkmark$ & $\checkmark$ & $\checkmark$ \\
\hline Predict Illness and Treatment & $\checkmark$ & $x$ & $\checkmark$ \\
\hline Health Information Management & $\checkmark$ & $\checkmark$ & $\checkmark$ \\
\hline Ambient Assistant Living & $\checkmark$ & $x$ & $\checkmark$ \\
\hline Internet of m-health & $\checkmark$ & $\checkmark$ & $\checkmark$ \\
\hline Insurance Management & $\checkmark$ & $\checkmark$ & $\checkmark$ \\
\hline Matching doctors with patients & $\checkmark$ & $x$ & $\checkmark$ \\
\hline Adverse Drug Reaction & $\checkmark$ & $x$ & $x$ \\
\hline Community Healthcare & $\checkmark$ & $\checkmark$ & $\checkmark$ \\
\hline Child healthcare & $\checkmark$ & $\checkmark$ & $\checkmark$ \\
\hline Wearable devices & $\checkmark$ & $\checkmark$ & $\checkmark$ \\
\hline Emergency healthcare & $\checkmark$ & $x$ & $x$ \\
\hline Mitgation of Viral Diseases & $\checkmark$ & $\checkmark$ & $x$ \\
\hline
\end{tabular}

\section{Case Study: Role of Machine Learning for Mitigating the Effect of COVID-19 Spread}

Machine learning can be used to reduce the spread of COVID-19 by using the KNN algorithm. In this case study, we assume that visitors are going to rate a building/medical center for the follow-up of COVID-19 health procedures. Figure 5 shows a building with multiple Sigfox end devices installed in multiple locations. These end devices have a rating collection mechanism, and the users are given an incentive by the building administration to share their rating for a particular place. This can be inside a shopping mall or a hospital setup, and the users basically share their rating data. If a locality is not following the SOPs required for COVID-19 mitigation, then the visitor will rate it accordingly. These rating data will be shared with the Sigfox base station, which will forward them towards a compute engine available on a cloud service for computing the rating of a particular place and make appropriate decisions. If the rating falls below a certain level, then the forthcoming visitors will take precautionary measures. This will help in reducing the propagation of the disease.

A Sigfox-based solution can transmit 140 packets having 12-byte payload in uplink per day. Thus, based on the location of the Sigfox device installed inside a building for rating data collection, a particular number of packets can be sent per day. If we combine data of multiple ratings in one packet, then we can even further optimize the efficiency of the system. Let us assume that we can combine up to 10 rating values in a packet (which is 
possible through packet fusion techniques [122]), then we can send up to 1400 rating data values per day.

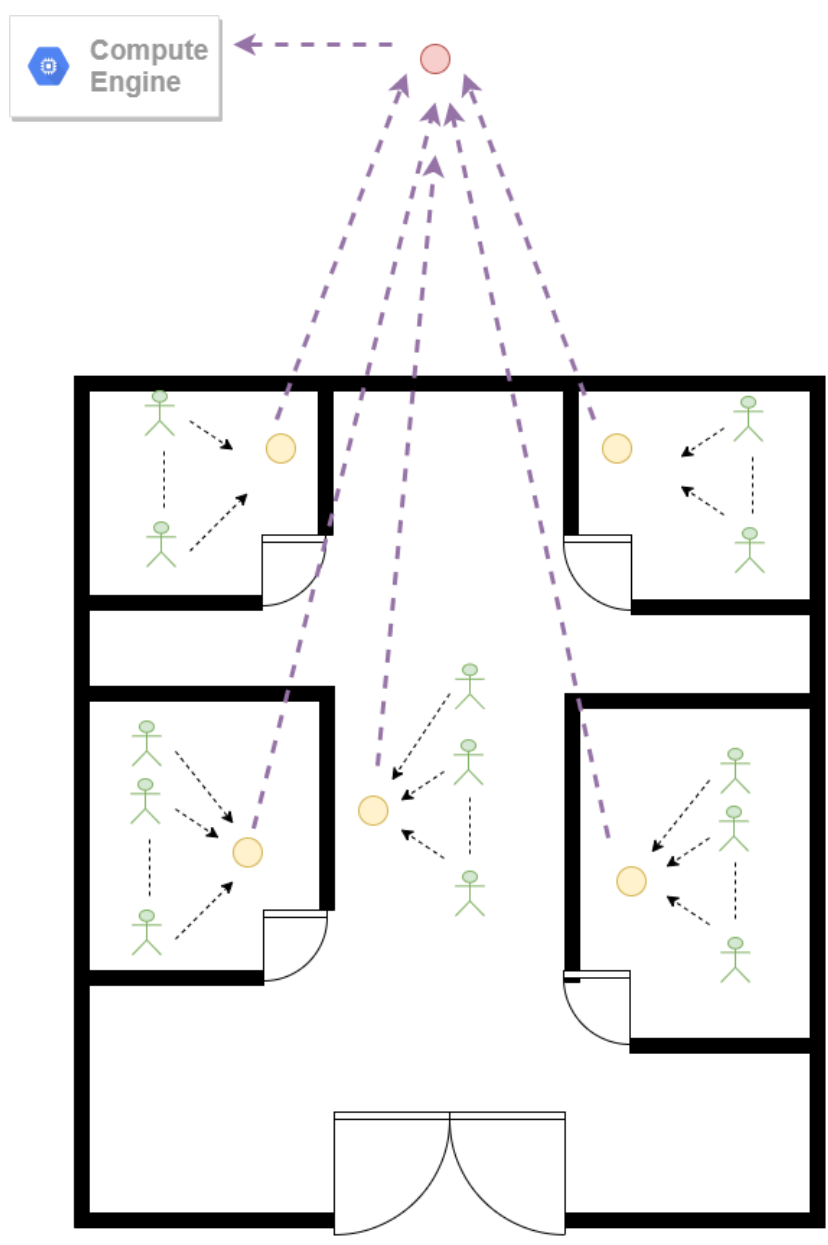

Sigfox based end device

\section{Sigfox base station}

Figure 5. Case study using Sigfox technology for uplink data transmission.

As depicted above, Sigfox devices can receive up to four messages per day having a payload of 8 bytes. It is assumed that these data are sent to particular Sigfox devices that have recommendation values less than a particular threshold. All these devices control a Liquid Crystal Display (LCD) to let the users know about the safety of a particular place, and they will generate an alarm based on the value displayed on the LCD. However, based on the downlink data transmission rate, this value can only be transmitted four times a day. For these calculations, it is pertinent to mention that we are assuming minimal data loss due to channel conditions. The downlink communication/message display mechanism is shown in Figure 6. This figure shows that the recommendation value for a particular place can be displayed on an LCD, which makes the users aware of the safety of a particular place. In the case safety values fall below a certain level, then the LCD would display the appropriate message. It is pertinent to mention here that LCDs are normally installed in a public place, and they can be reused by our proposed case study.

Another mechanism is to forward the safety parameter values to the local municipal administration or the building management for further necessary action. This is to ensure that a panic signal is not sent to the building users directly; however, the local municipal 
administration or building management can make appropriate decisions. This type of proposal is depicted in Figure 7. Another idea is to combine the concept of both models described in Figures 6 and 7, by simultaneously sending the data to local authorities and the Sigfox end devices. The transmission requirements for uplink and downlink for different scenarios is depicted in Table 3.

Table 3. Maximum packet transmissions and receptions through the Sigfox network for the case study.

\begin{tabular}{lccc}
\hline $\begin{array}{l}\text { Sigfox Packet } \\
\text { Transmissions }\end{array}$ & $\begin{array}{c}\text { Rating Data Values } \\
\text { Transmitted } \\
\text { per Day per Device }\end{array}$ & $\begin{array}{c}\text { Safety Parameter Transmissions } \\
\text { per Day, per Device } \\
\text { (to be Displayed on LCD) }\end{array}$ & $\begin{array}{c}\text { Safety Parameter Transmissions } \\
\text { per Day, per Device } \\
\text { (to be Sent to the Authorities) }\end{array}$ \\
\hline Uplink & 1400 & 0 & 0 \\
\hline Downlink & 0 & 4 & 4 \\
\hline
\end{tabular}

In the following subsections, we describe the rating mechanism and $\mathrm{KNN}$ algorithm for the case study. We performed two experiments. The first experiment tested the rating mechanism using KNN. The second experiment compared the KNN algorithm to other techniques.

\subsection{Experiment 1: Rating Data Management using KNN}

In this section, we describe a mechanism for managing the rating data for a certain place to do further predictions. We devise a strategy to gather these data. Furthermore, the rating data are used by KNN algorithm to train and generate the boundaries for classification. Then, the rest of the data are used by the KNN algorithm to test the generated model, which is also summarized in Figure 8. The following sections describe Experiment 1 in detail.

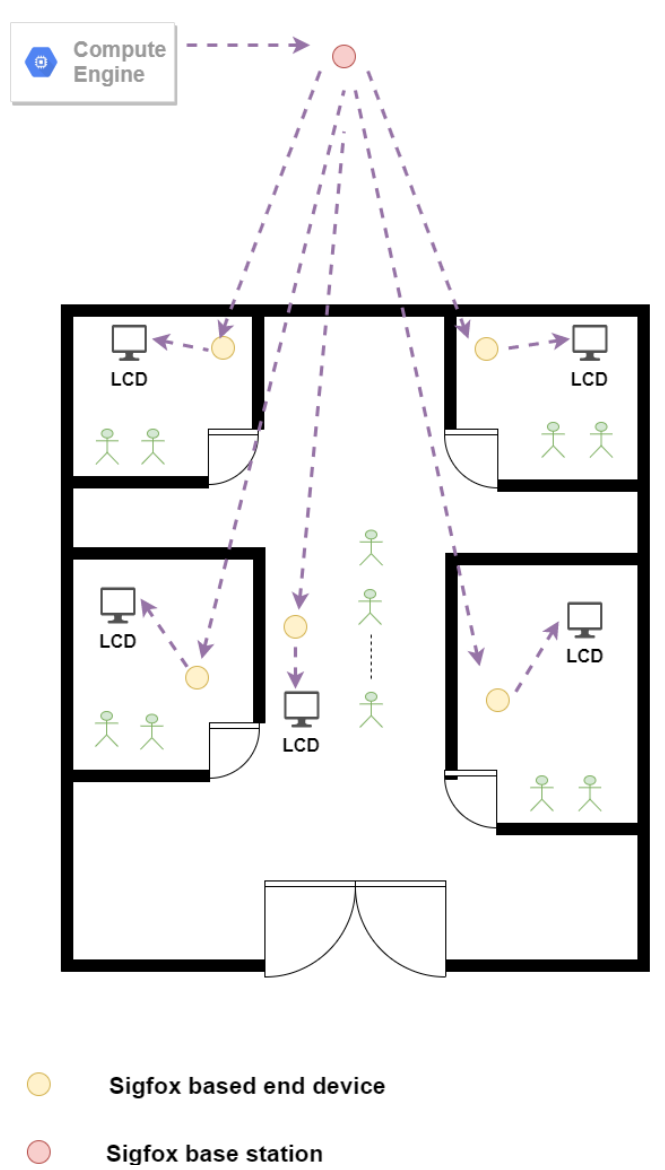

Figure 6. Case study using Sigfox technology for downlink data transmission to display on an LCD. 


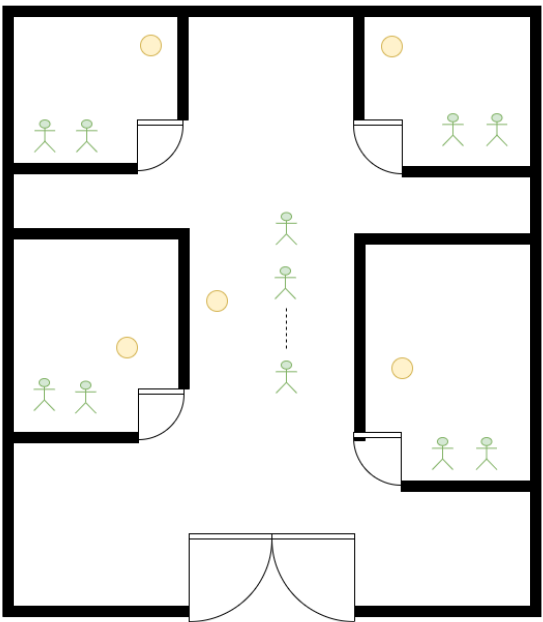

Sigfox based end device

Sigfox based end device controlled by the

Sigfox base station relevant authorities

Figure 7. Case study using Sigfox technology for downlink data transmission to alert the authorities.

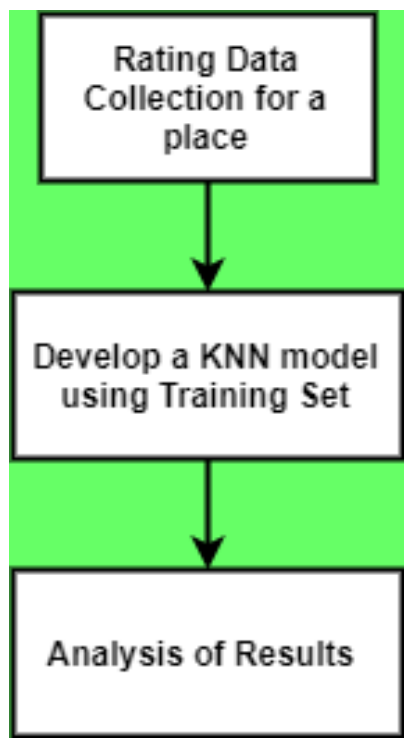

Figure 8. Simulation model.

\subsubsection{Rating Data Collection}

In this case study, we consider three metrics, i.e., belief, $b$; disbelief, $d$; and uncertainty, $u$, for a certain place about COVID-19 regulations using the model described in [123]. The belief of person $i$ on a place $j\left(b_{i, j}\right)$ increases after the person is sure that the place is following the COVID-19 SOPs correctly, while disbelief of a person $i$ on place $j\left(d_{i, j}\right)$ increases in the case the place is not following the COVID-19 regulations. If an interaction did not happen between a person and a geographical place, then the uncertainty of person $i$ on place $j\left(u_{i, j}\right)$ would increase. The respective equations of these three factors are given below: 


$$
\begin{aligned}
b_{i, j} & =\frac{p_{i, j}}{\left(p_{i, j}+n_{i, j}+1\right)} \\
d_{i, j} & =\frac{n_{i, j}}{\left(p_{i, j}+n_{i, j}+1\right)} \\
u_{i, j} & =\frac{1}{\left(p_{i, j}+n_{i, j}+1\right)}
\end{aligned}
$$

Here, positive and negative interactions between person $i$ and place $j$ are described by $p_{i, j}$ and $n_{i, j}$, respectively. If an interaction did not happen between person $i$ and place $j$, then this escalates the uncertainty about that place. These values are passed to the government agency for using the KNN algorithm to combine these values. These are based on opinion triangle, which is given in Figure 9.

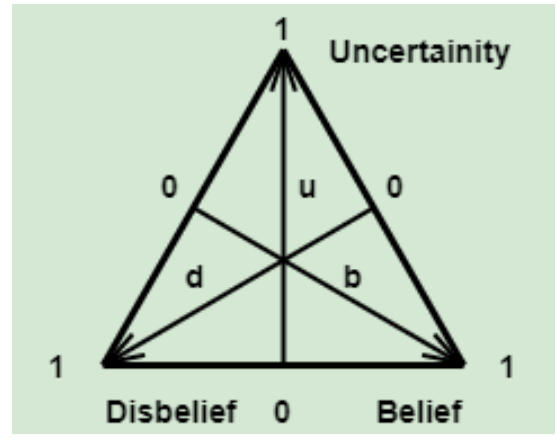

Figure 9. Opinion triangle.

These three metrics are used for user data rating about a particular place. This place can be inside a healthcare center or any other location where people gather, and it can become hot spot of the virus propagation.

\subsubsection{KNN Based Rating Mechanism}

Using the COVID-19-related data extracted in the previous subsection, the data are combined using $\mathrm{KNN}$ algorithm for getting the rating. As described above, the k-nearest neighbor algorithm can be applied to classification, as well as regression problems. We use this algorithm to classify a place inside a building as safe or unsafe for visitors based on past interactions of the people. Thus, the people will rate a building as it can be used to minimize the spread of disease. The dataset consists of randomly generated trust values for a particular building. The method will use $70 \%$ of values for training and the remaining $30 \%$ for testing purposes.

\subsubsection{Simulation Results for Experiment 1}

As described in the previous subsection, the rating data are generated for a particular location. We use $70 \%$ of values to train the $\mathrm{KNN}$ model using a $50 \%$ positive trust threshold value to label it. Based on the obtained model, the remaining 30\% of values are checked for the accuracy of classification.

Finally, KNN algorithm is used in an Octave program (available at [124]), to get the results on the $30 \%$ dataset. We define two parameters for evaluation, i.e., false positive and false negative, as follows:

False Negative: The rating value is a positive one for a place, but KNN declares it as an unhealthy place.

False Positive: The rating value labels a place as unhealthy, but KNN model classifies it to be a healthy one.

The correct detection results are presented in Figure 10 and the false negatives and false positive results are given in Figures 11 and 12. The results show that, if the positive trust detection threshold is less than 0.5, then it is giving more errors. However, once we increase the positive trust level to be greater than 0.5 , the errors start to decrease and we get better results. Hence, it seems that the KNN algorithm is providing better results using the dataset, once the trust threshold is beyond the $50 \%$ value. Similar results are observed 
for false positive and false negative, and the value of these error indicating factors decrease if the trust threshold is greater than $50 \%$.

This method gives an idea about the accuracy of using the KNN for reputation management in COVID-19 use cases. In the next subsection, a comparison between KNN and subjective logic is described using another experiment.

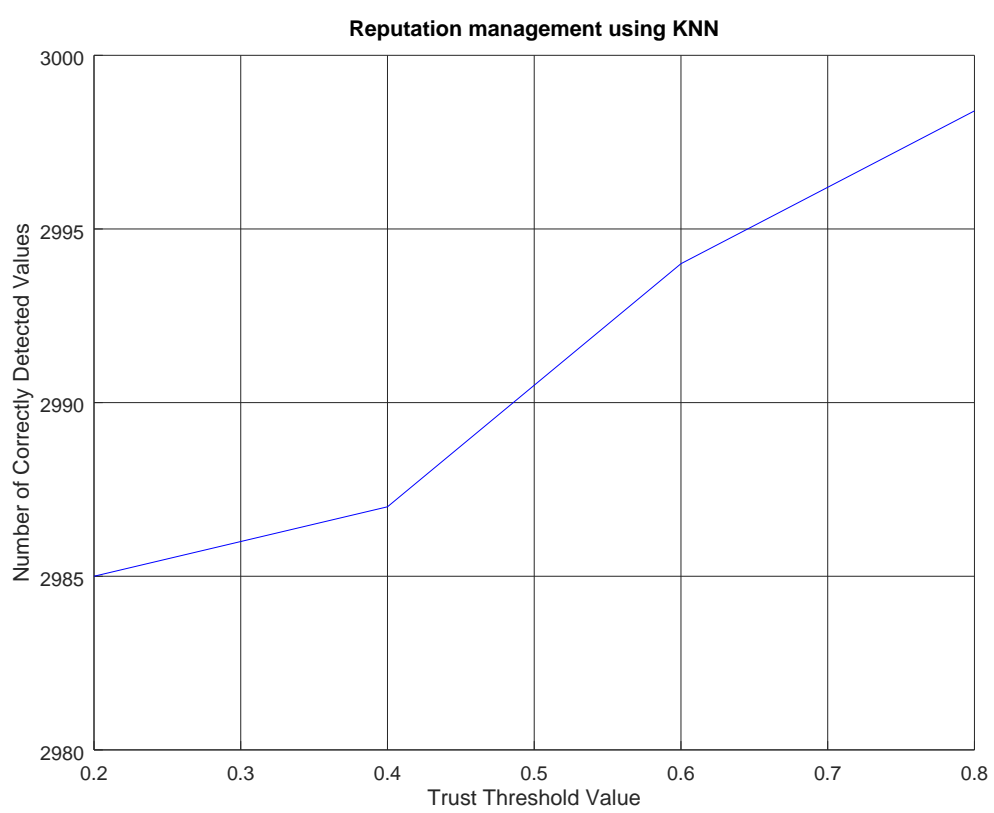

Figure 10. Reputation management using KNN.

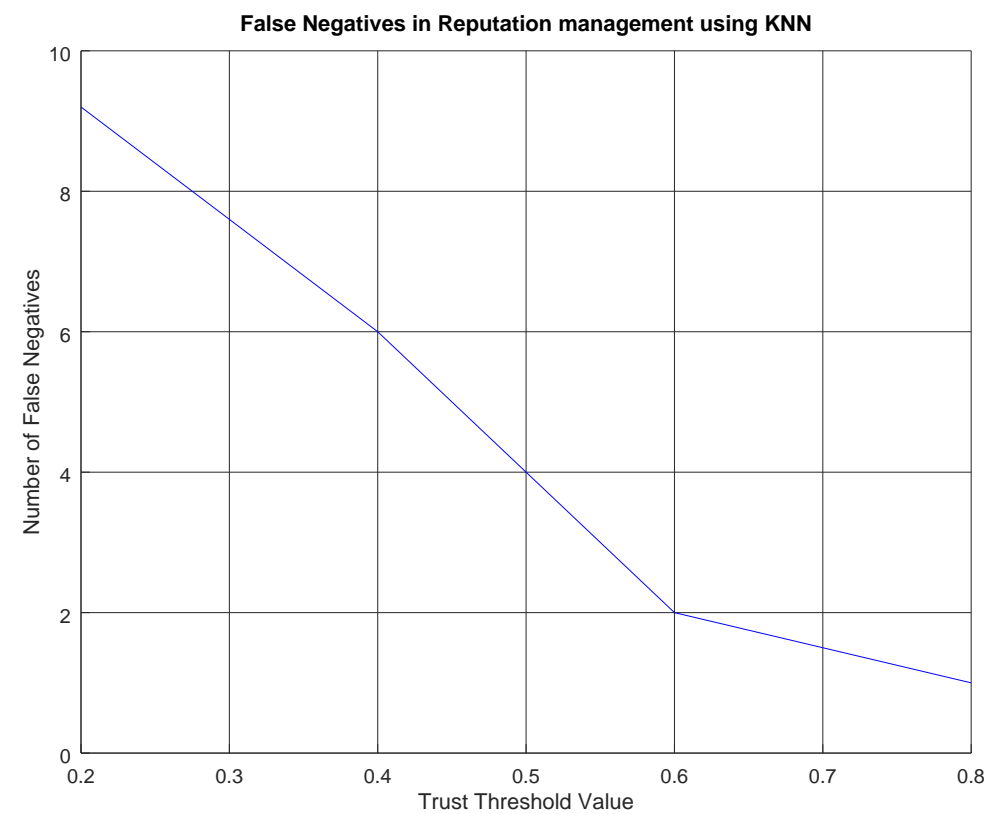

Figure 11. False negatives in reputation management using KNN. 


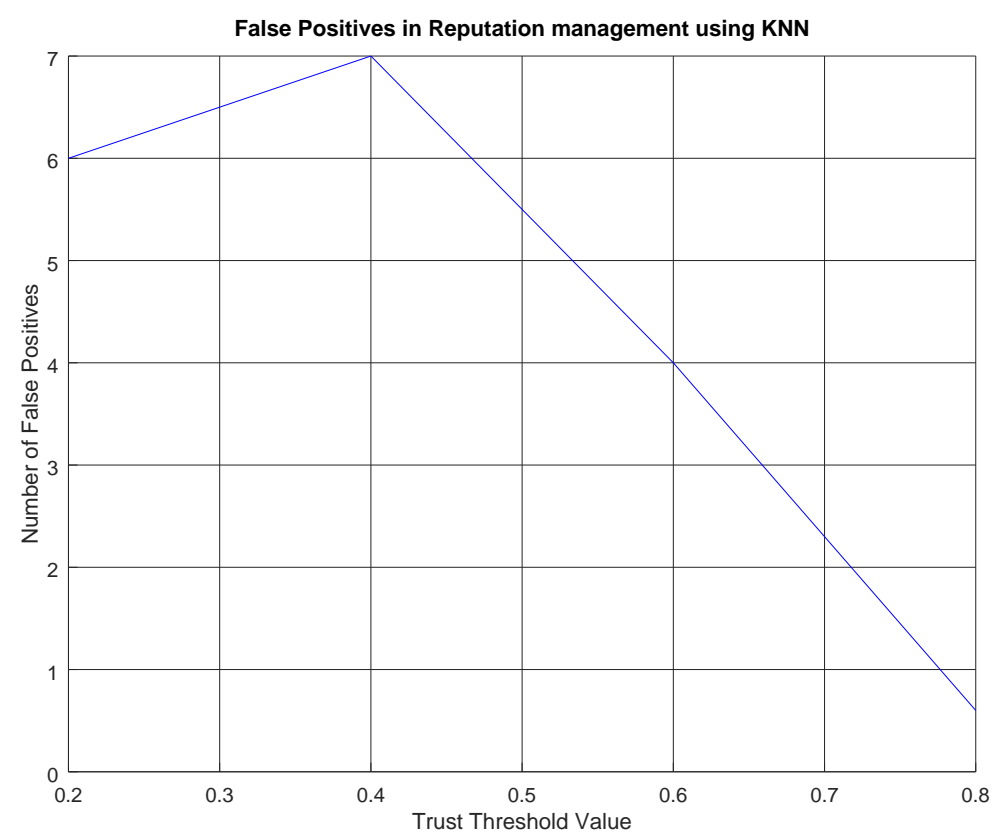

Figure 12. False positives in reputation management using KNN.

\subsection{Experiment 2: Rating a Place for COVID-19}

In Experiment 2, we use KNN and subjective logic to combine the rating of a place. The users who visit this place give it a positive, negative, or uncertain rating about the presence of the COVID-19 virus. Then, we use KNN and subjective logic to evaluate and generate recommendation. In the following section, we first explain subjective logic, followed by the combining mechanism.

\subsubsection{Subjective Logic for Rating Mechanism}

The operators available for subjective logic can be used to combine the opinion values about a certain place are described in [123]. Here, successful and unsuccessful interactions between entities $i$ and $j$ are given by $p_{i, j}$ and $n_{i, j}$, respectively. However, uncertainty is given by factor $u_{i, j}$. For example, if a person $i$ finds a place $j$ to be healthy with respect to COVID-19, then it is counted as a positive interaction. On the other hand, if a person $i$ finds a place $j$ to be unhealthy, then it is labeled as a negative interaction. Finally, if a person $i$ cannot judge a place $j$ as healthy or unhealthy, then uncertainty about that particular place is increased. These values are passed to the consensus operator, which gives us the overall recommendations of the place. The commutative and associative consensus operator described in [123] is used to merge these values in the form of overall recommendation, which is given below:

$$
w_{r_{1} x} \oplus w_{r_{2} x} \triangleq \frac{b_{r_{1} x} u_{r_{2} x}+b_{r_{2} x} u_{r_{1} x}}{k}, \frac{d_{r_{1} x} u_{r_{2} x}+d_{r_{2} x} u_{r_{1} x}}{k}, \frac{u_{r_{1} x} u_{r_{2} x}}{k}
$$

The formula describes recommendations by two people, $r_{1}$ and $r_{2}$. The combined recommendation is given by $w_{r_{1} x}=\left(b_{r_{1} x}, d_{r_{1} x}, u_{r_{1} x}\right)$ and $w_{r_{2} x}=\left(b_{r_{2} x}, d_{r_{2} x}, u_{r_{2} x}\right)$, while $k$ is given by $u_{r_{1} x}+u_{r_{2} x}-u_{r_{1} x} u_{r_{2} x}$.

\subsubsection{Simulation Results for Experiment 2}

In this section, the simulation results for Experiment 2 are described. The rating data are randomly generated using the Octave program and labeled to be safe or unsafe based on the combined ratings. The ratings are combined using KNN and subjective logic.

First, the dataset is generated using the parameters belief, $b$; disbelief, $d$; and uncertainty, $u$.

These values return the reputation of a place inside a building based on the COVID-19 SOPs. If persons in a location are following these SOPs, then it is assigned a positive rating, 
otherwise a negative one. If a user is unsure about the place it is visiting, then it will be given an uncertain value. Then, it is assigned a positive rating by varying the belief value.

KNN first trains the model using $70 \%$ of the data and the remaining $30 \%$ of data are used in recommending the place. KNN uses a voting mechanism for recommendation. If a rating seems to be positive, then $\mathrm{KNN}$ will increase the positive count about the place, otherwise it will increase the negative count. If the positive count is greater than negative, then the building is classified as healthy. On the contrary, if the negative count is greater, then it is classified as unhealthy place. This mechanism is described in Algorithm 1.

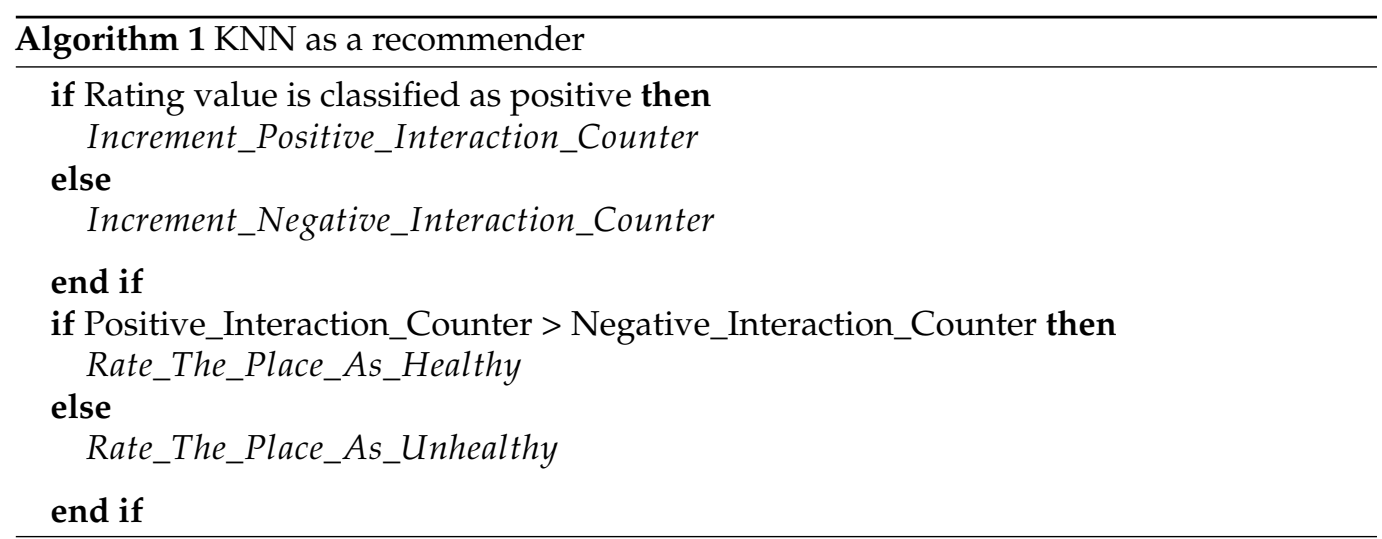

The comparisons of KNN and subjective logic is given in Figure 13, while Figure 14 gives the comparison by varying the threshold of subjective logic. The results show that for six difference datasets the rating performance of both techniques is quite similar. However, subjective logic needs to locate an optimal threshold for the detection. If we vary the threshold from 0.4 to 0.6 , in steps of 0.2 , then subjective logic sometimes gives a positive recommendation but for other cases gives a negative recommendation. On the contrary, the rating mechanism of $\mathrm{KNN}$ is based on classification. Hence, it does not need to locate a particular threshold for detection. Therefore, we conclude that KNN is a better algorithm in terms of complexity for rating a particular place.

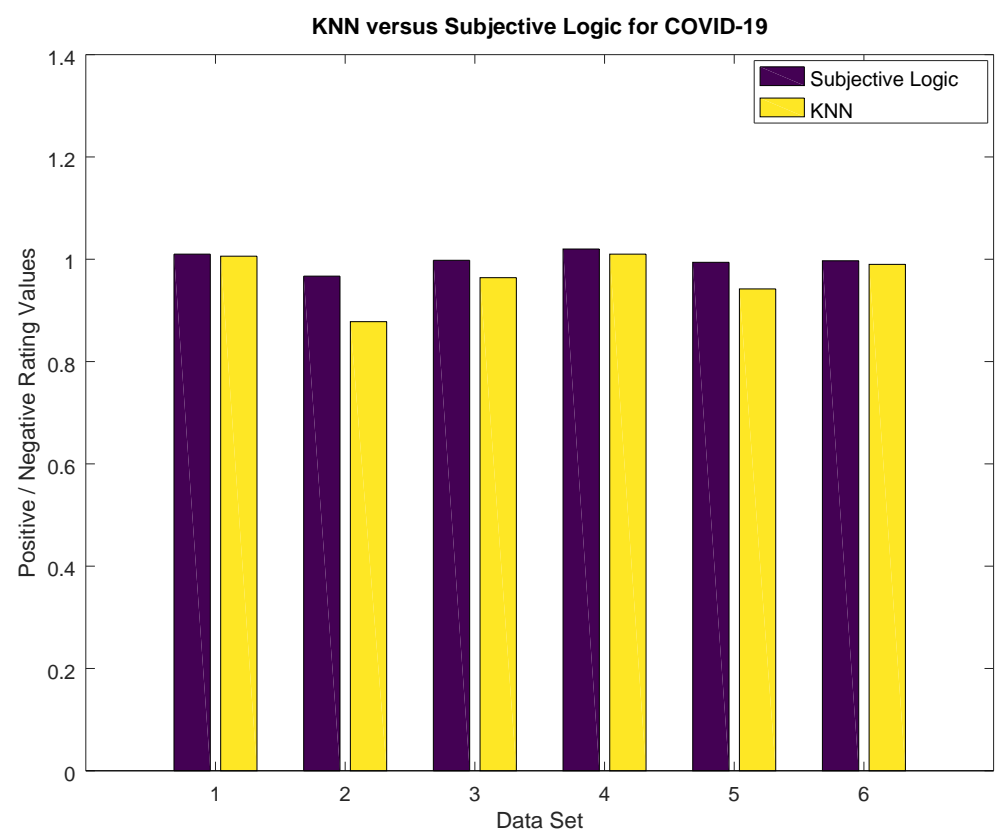

Figure 13. KNN vs. subjective logic for COVID-19 application. 


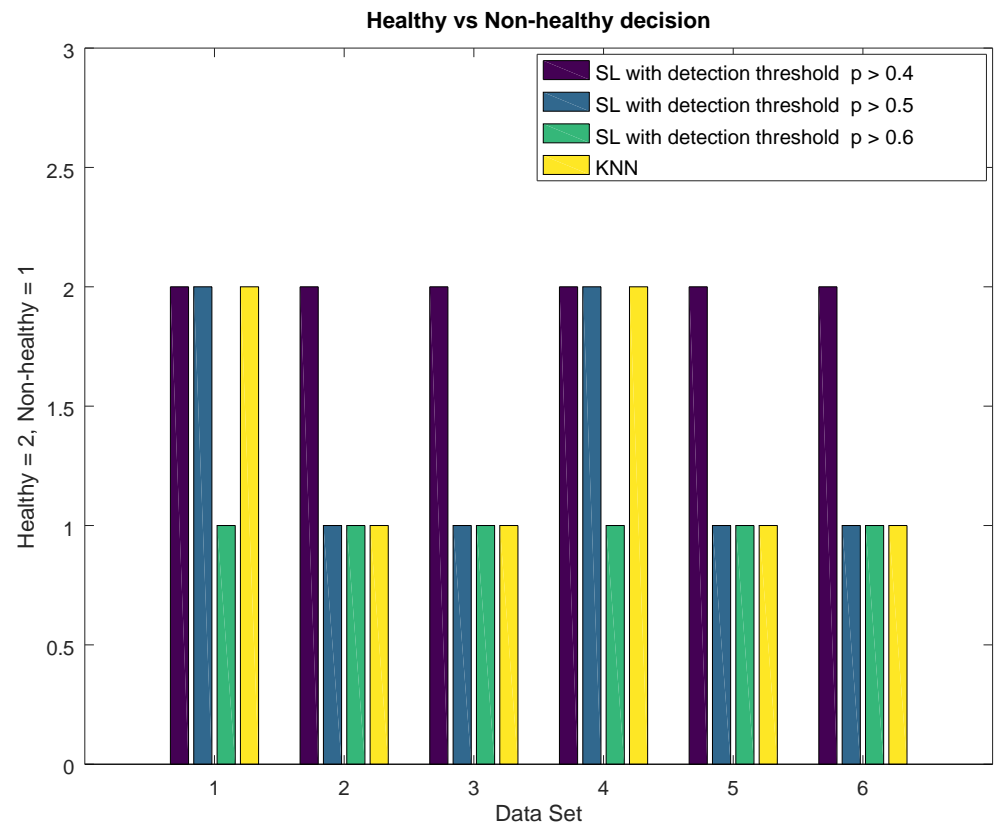

Figure 14. Comparison of KNN vs. subjective logic with varying threshold values.

Finally, if the rating of a building falls below a certain threshold value, then it needs to be investigated for violations. Hence, the authorities will make an appropriate decision about the violators. The results help in assessing the health-related SOPs being followed in a place and results in prevention of further disease spread, especially COVID-19. Based on the virus spread, the authorities may decide about the threshold level, which in turn helps rectify the situation. Secondly, it will help in making the decision about visiting a place.

Figures 6 and 7 explain the mechanism that is initiated by the base station in the case the rating of a building falls below a certain threshold. The processing engine in these models may use the machine learning and trust-based algorithms described in this case study. Hence, this mechanism may provide a mechanism to end users or the building management/municipal committee to take necessary measures for mitigating the spread of viral diseases.

\section{Discussion and the Perspective Work}

The COVID-19 pandemic has brought the world an unseen scenario. One of the solutions to curtail it is by using social distancing, and LPWAN technology is helping the healthcare industry to achieve that. Therefore, during the pandemic, LPWAN technology is used in two ways to control the situation, i.e., directly and indirectly [125]. This article proposes further uses of LPWAN and machine learning for minimizing the damage of COVID-19 in direct and indirect manners.

As mentioned above, social distancing is one way to reduce the spread of COVID-19. For healthcare professionals, this means that minimizing contact with patients is important, so that they can be safe from this disease. We describe various applications and services of LPWAN-based healthcare systems in this article, which can be used in this outbreak. These include body area network deployment, illness prediction and treatment, health information management, AAL, Internet of m-health, matching doctors with patients, vital signs monitoring, adverse drug reaction, community healthcare, child healthcare, and insurance management. All these services and applications minimize the contact between patients and healthcare providers. Thus, they protect the healthcare staff, by providing high-quality treatments to patients.

Some infected patients or perceived-to-be-infected people are placed in quarantine at home. Another application of LPWAN-based systems in the healthcare sector is by doing quarantine tracking of these people. This information can be provided to the healthcare sectors or governments for effective controlling of patients [126]. Similarly, some hospitals 
were setup using LPWAN and machine learning in Wuhan, China, to provide quality healthcare to the people.

LPWAN and machine learning can provide features which can be used in an indirect way to curtail the spread of COVID-19 [127]. The people-to-people contact has to be minimized in this situation, and the prime areas to target are educational institutes and business centers. Schools and educational institutes have been closed for months. Education is being provided online. Teachers and students have started using various LPWAN gadgets for the ease of this online education. It is similar in business centers, as LPWAN-based smart shelves have been introduced for providing social distancing and minimizing human interaction.

This article describes a case study for minimizing the spread of disease by developing an application which can rate a place for COVID-19 risk level. Based on this risk assessment, the place can be regarded as safe or unsafe, and this application can be deployed in hospitals and other crowded places. However, the utility of this study needs to be checked for a real-world scenario. Furthermore, all the healthcare services explained in this article need to be deployed in real life to measure their effectiveness.

\section{Conclusions}

In this article, we present the usage of Internet of Things for the case of COVID-19 scenario. The world has changed as a result of the current pandemic situation, and technology is integrating into our lives. The IoT can help us to mitigate the spread of COVID-19, which is discussed with the help of a case study. First, we discuss the background of IoT/LPWAN and machine learning and how it can be used in healthcare sector. There are numerous applications that we can find in the healthcare sector using machine learning and IoT/LPWAN. Various healthcare services can be derived from this infrastructure for the COVID-19 scenario. Finally, we discuss a case study which describes the direct as well as indirect use of IoT/LPWAN for mitigating the spread of COVID-19. We did some simulations to show the effectiveness of the KNN algorithm for mitigating the flow of virus spread. The KNN algorithm is compared with other techniques to show its better performance over other state-of-the-art techniques. The case study uses the Sigfox proprietary technology to pass the rating values to a remote compute engine, through a Sigfox base station. If an alert has to be generated, then it can be either displayed on LCD available in the building or sent to the local authorities for further necessary action.

As a perspective work, we propose to use various other machine learning techniques for optimizing LPWAN-based healthcare applications in COVID-19. We also propose to explore innovative applications using LPWAN technology and machine learning to further help in the COVID-19 scenario. We discuss numerous machine learning-based applications, which require LPWAN technology for long-distance transmission of medical data. Another perspective work is to implement the proposed case study in a real environment and check its usability.

Author Contributions: Conceptualization, Z.A.K. and U.A.; methodology, Z.A.K., U.A. and S.W.K.; investigation, Z.A.K. and U.A.; resources, Z.A.K., U.A. and S.W.K.; writing - original draft preparation, Z.A.K. and U.A.; writing-review and editing, Z.A.K., U.A. and S.W.K.; supervision, S.W.K.; funding acquisition, S.W.K. All authors have read and agreed to the published version of the manuscript.

Acknowledgments: This research was supported in part by the MSIT (Ministry of Science and ICT), Korea, under the ITRC (Information Technology Research Center) support program (IITP-2021-20160-00313) supervised by the IITP (Institute for Information \& Communications Technology Planning \& Evaluation) and in part by Basic Science Research Program through the National Research Foundation of Korea (NRF) funded by the Ministry of Education (2018R1D1A1A09082266).

Conflicts of Interest: The authors declare no conflict of interest. 


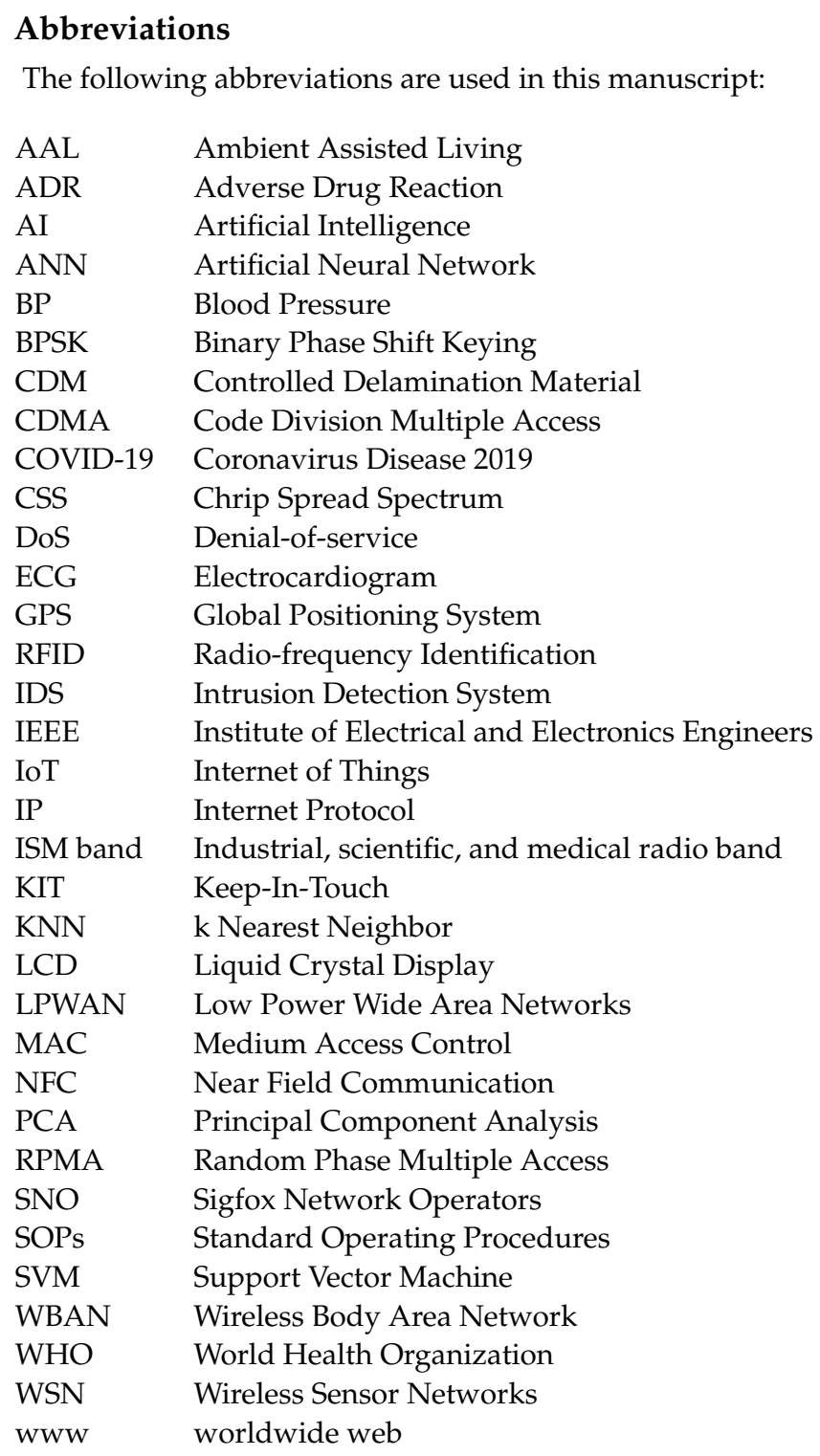

\section{References}

1. Gartner Identifies the Top 10 Internet of Things Technologies for 2017 and 2018. Available online: https://www.gartner.com/en/ newsroom/press-releases / 2016-02-23-gartner-identifies-the-top-10-internet-of-things-technologies-for-2017-and-2018 (accessed on 14 May 2021).

2. Chaudhari, B.S.; Zennaro, M.; Borkar, S. LPWAN Technologies: Emerging Application Characteristics, Requirements, and Design Considerations. Future Internet 2020, 12, 46. [CrossRef]

3. Melakessou, F.; Kugener, P.; Alnaffakh, N.; Faye, S.; Khadraoui, D. Heterogeneous Sensing Data Analysis for Commercial Waste Collection. Sensors 2020, 20, 978. [CrossRef] [PubMed]

4. Raza, U.; Kulkarni, P.; Sooriyabandara, M. Low Power Wide Area Networks: An Overview. IEEE Commun. Surv. Tutorials 2017, 19, 855-873. [CrossRef]

5. Abo-Tabik, M.; Costen, N.; Darby, J.; Benn, Y. Towards a Smart Smoking Cessation App: A 1D-CNN Model Predicting Smoking Events. Sensors 2020, 20, 1099. [CrossRef]

6. Sun, J.; Fang, Y.; Zhu, X. Privacy and emergency response in e-healthcare leveraging wireless body sensor networks. IEEE Wirel. Commun. 2010, 17, 66-73. [CrossRef]

7. Liu, T.; Xu, H.; Ragulskis, M.; Cao, M.; Ostachowicz, W. A Data-Driven Damage Identification Framework Based on Transmissibility Function Datasets and One-Dimensional Convolutional Neural Networks: Verification on a Structural Health Monitoring Benchmark Structure. Sensors 2020, 20, 1059. [CrossRef]

8. Pradhan, B.; Bhattacharyya, S.; Pal, K. IoT-Based Applications in Healthcare Devices. J. Healthc. Eng. 2021, 2021, 6632599. [CrossRef]

9. She, J.; Jiang, J.; Ye, L.; Hu, L.; Bai, C.; Song, Y. 2019 novel coronavirus of pneumonia in Wuhan, China: Emerging attack and management strategies. Clin. Transl. Med. 2020, 9, 1-7. [CrossRef] [PubMed] 
10. Preventing the Spread of the Coronavirus. Available online: https://www.health.harvard.edu/diseases-and-conditions / preventing-the-spread-of-the-coronavirus (accessed on 10 June 2021).

11. Ullah, A.; Azeem, M.; Ashraf, H.; Alaboudi, A.A.; Humayun, M.; Jhanjhi, N. Secure Healthcare Data Aggregation and Transmission in IoT-A Survey. IEEE Access 2021, 9, 16849-16865. [CrossRef]

12. Qadri, Y.A.; Nauman, A.; Zikria, Y.B.; Vasilakos, A.V.; Kim, S.W. The Future of Healthcare Internet of Things: A Survey of Emerging Technologies. IEEE Commun. Surv. Tutorials 2020, 22, 1121-1167. [CrossRef]

13. Olatinwo, D.D.; Abu-Mahfouz, A.; Hancke, G. A survey on LPWAN technologies in WBAN for remote health-care monitoring. Sensors 2019, 19, 5268. [CrossRef]

14. Khan, Z.A.; Abbasi, U. Evolution of Wireless Sensor Networks toward Internet of Things. In Emerging Communication Technologies Based on Wireless Sensor Networks: Current Research and Future Applications; CRC Press: Boca Raton, FL, USA, 2016; Chapter 7, pp. 179-200.

15. Giusto, D.; Iera, A.; Morabito, G.; Atzori, L. The Internet of Things: 20th Tyrrhenian Workshop on Digital Communications; Springer Science \& Business Media: Berlin/Heidelberg, Germany, 2010.

16. National Intelligence Council, Disruptive Civil Technologies-Six Technologies with Potential Impacts on US Interests Out to 2025. Available online: http://globaltrends.thedialogue.org/publication/disruptive-civil-technologies-six-technologies-withpotential-impacts-on-us-interests-out-to-2025/ (accessed on 17 September 2020).

17. European Commission Report on Internet of Things. Available online: https://ec.europa.eu/digital-single-market/en/internetof-things (accessed on 17 September 2020).

18. International Telecomunicaciones Union (ITU). Recommendation ITU-T Y.4000/Y.2060 (2012), Overview of the Internet of Things. 2012. Available online: https:/ /www.itu.int/rec/T-REC-Y.2060-201206-I (accessed on 17 June 2020).

19. Vermesan, O.; Friess, P.; Guillemin, P.; Gusmeroli, S.; Sundmaeker, H.; Bassi, A.; Jubert, I.; Mazura, M.; Harrison, M.; Eisenhauer, M.; et al. Internet of Things Strategic Research Roadmap. 2009. Available online: https://www.sintef.no/en/publications/ publication/?pubid=CRIStin+911003 (accessed on 17 September 2020).

20. Ray, P. A survey on Internet of Things architectures. J. King Saud Univ. Comput. Inf. Sci. 2018, 30, 291-319. [CrossRef]

21. Ray, B. The Past, Present, and Future of LPWAN. Available online: https://www.link-labs.com/blog/past-present-future-lpwan (accessed on 10 June 2020).

22. Low-Power Wide Area Network (LPWAN) Overview. Available online: https://tools.ietf.org/pdf/rfc8376.pdf (accessed on 17 May 2020).

23. Foubert, B.; Mitton, N. Long-range wireless radio technologies: A survey. Future Internet 2020, 12, 13. [CrossRef]

24. Amadou, I.; Foubert, B.; Mitton, N. LoRa in a haystack: A study of the LORA signal behavior. In Proceedings of the 2019 International Conference on Wireless and Mobile Computing, Networking and Communications (WiMob), Barcelona, Spain, 21-23 October 2019; pp. 1-4.

25. Nugraha, A.T.; Hayati, N.; Suryanegara, M. The experimental trial of LoRa system for tracking and monitoring patient with mental disorder. In Proceedings of the 2018 International Conference on Signals and Systems (ICSigSys), Bali, Indonesia, 1-3 May 2018; pp. 191-196.

26. European Commission. Green Paper on Mobile Health. Available online: https://ec.europa.eu/digital-single-market/en/news/ green-paper-mobile-health-mhealth (accessed on 17 May 2020).

27. European Commission. Public Consultation on the Green Paper on Mobile Health. Available online: https: / / digital-strategy.ec. europa.eu/en/library/summary-report-public-consultation-green-paper-mobile-health (accessed on 17 May 2020).

28. 5G and e-Health. Available online: https://5g-ppp.eu/wp-content/uploads/2016/02/5G-PPP-White-Paper-on-eHealthVertical-Sector.pdf (accessed on 17 May 2020).

29. Thuemmler, C.; Paulin, A.; Jell, T.; Lim, A.K. Information Technology-Next Generation: The Impact of 5G on the Evolution of Health and Care Services. In Information Technology—New Generations; Latifi, S., Ed.; Springer International Publishing: Cham, Swizerland, 2018; pp. 811-817.

30. European Commission. MHealth, What Is It?-Infographic. Available online: https:/ / ec.europa.eu/digital-single-market/en/ news / mhealth-what-it-infographic (accessed on 17 May 2020).

31. Global Asthma Network: The Global Asthma Report for 2014. Available online: http:/ /www.globalasthmareport.org/ (accessed on 19 May 2020).

32. Roland, D.; Lantauro, I. Google Parent and Sanofi Name Diabetes Joint Venture Onduo. Available online: http://www.wsj.com/ articles / google-parent-and-sanofi-name-diabetes-joint-venture-onduo-1473659627 (accessed on 19 May 2020).

33. Mekki, K.; Bajic, E.; Chaxel, F.; Meyer, F. A comparative study of LPWAN technologies for large-scale IoT deployment. ICT Express 2019, 5, 1-7. [CrossRef]

34. Khan, Z.A.; Auguin, M. A Multichannel Design for QoS Aware Energy Efficient Clustering and Routing in WMSN. Int. J. Sen. Netw. 2013, 13, 145-161. [CrossRef]

35. An Introduction to Machine Learning. Available online: https://www.digitalocean.com/community/tutorials/an-introductionto-machine-learning (accessed on 10 January 2020).

36. Li, Y.F.; Guo, L.Z.; Zhou, Z.H. Towards Safe Weakly Supervised Learning. IEEE Trans. Pattern Anal. Mach. Intell. 2021, 43, 334-346. [CrossRef] 
37. Wang, X.; Kihara, D.; Luo, J.; Qi, G.J. EnAET: A Self-Trained Framework for Semi-Supervised and Supervised Learning With Ensemble Transformations. IEEE Trans. Image Process. 2021, 30, 1639-1647. [CrossRef]

38. Shang, C.; Chang, C.Y.; Chen, G.; Zhao, S.; Lin, J. Implicit Irregularity Detection Using Unsupervised Learning on Daily Behaviors. IEEE J. Biomed. Health Inform. 2020, 24, 131-143. [CrossRef] [PubMed]

39. Zhang, Z.; Wang, D.; Gao, J. Learning Automata-Based Multiagent Reinforcement Learning for Optimization of Cooperative Tasks. IEEE Trans. Neural Netw. Learn. Syst. 2020, 1-14. [CrossRef] [PubMed]

40. Zhang, W.; Chen, X.; Liu, Y.; Xi, Q. A Distributed Storage and Computation k-Nearest Neighbor Algorithm Based Cloud-Edge Computing for Cyber-Physical-Social Systems. IEEE Access 2020, 8, 50118-50130. [CrossRef]

41. Bharadwaj, H.K.; Agarwal, A.; Chamola, V.; Lakkaniga, N.R.; Hassija, V.; Guizani, M.; Sikdar, B. A Review on the Role of Machine Learning in Enabling IoT Based Healthcare Applications. IEEE Access 2021, 9, 38859-38890. [CrossRef]

42. Posonia, A.M.; Vigneshwari, S.; Rani, D.J. Machine Learning based Diabetes Prediction using Decision Tree J48. In Proceedings of the 2020 3rd International Conference on Intelligent Sustainable Systems (ICISS), Tirunelveli, India, 17-18 December 2020; pp. 498-502. [CrossRef]

43. Kim, T.; Vecchietti, L.F.; Choi, K.; Lee, S.; Har, D. Machine Learning for Advanced Wireless Sensor Networks: A Review. IEEE Sens. J. 2021, 21, 12379-12397. [CrossRef]

44. Gu, T. Detection of Small Floating Targets on the Sea Surface Based on Multi-Features and Principal Component Analysis. IEEE Geosci. Remote Sens. Lett. 2020, 17, 809-813. [CrossRef]

45. Hoang, T.M.; Duong, T.Q.; Tuan, H.D.; Lambotharan, S.; Hanzo, L. Physical Layer Security: Detection of Active Eavesdropping Attacks by Support Vector Machines. IEEE Access 2021, 9, 31595-31607. [CrossRef]

46. Kaur, R.; Singh, A.; Singla, J. Integration of NIC algorithms and ANN: A review of different approaches. In Proceedings of the 2021 2nd International Conference on Computation, Automation and Knowledge Management (ICCAKM), Dubai, United Arab Emirates, 19-21 January 2021; pp. 185-190. [CrossRef]

47. Daza, E.J.; Wac, K.; Oppezzo, M. Effects of Sleep Deprivation on Blood Glucose, Food Cravings, and Affect in a Non-Diabetic: An N-of-1 Randomized Pilot Study. Healthcare 2020, 8, 6. [CrossRef] [PubMed]

48. Istepanian, R.S.H.; Hu, S.; Philip, N.Y.; Sungoor, A. The potential of Internet of m-health Things (m-IoT) for non-invasive glucose level sensing. In Proceedings of the 2011 Annual International Conference of the IEEE Engineering in Medicine and Biology Society, Boston, MA, USA, 30 August-3 September 2011; pp. 5264-5266.

49. Lijun, Z. Multi-parameter medical acquisition detector based on Internet of Things. Chin. Pat. 2013, $202,774$.

50. Niu, L.; Chen, C.; Liu, H.; Zhou, S.; Shu, M. A Deep-Learning Approach to ECG Classification Based on Adversarial Domain Adaptation. Healthcare 2020, 8, 437. [CrossRef]

51. Drew, B.J.; Califf, R.M.; Funk, M.; Kaufman, E.S.; Krucoff, M.W.; Laks, M.M.; Macfarlane, P.W.; Sommargren, C.; Swiryn, S.; Hare, G.F.V. Practice Standards for Electrocardiographic Monitoring in Hospital Settings. Circulation 2004, 110, $2721-2746$. [CrossRef]

52. Dash, P. Electrocardiogram Monitoring. Indian J. Anaesth. 2002, 46, 251-260.

53. Yang, G.; Xie, L.; Mantysalo, M.; Zhou, X.; Pang, Z.; Xu, L.D.; Kao-Walter, S.; Chen, Q.; Zheng, L. A Health-IoT Platform Based on the Integration of Intelligent Packaging, Unobtrusive Bio-Sensor, and Intelligent Medicine Box. IEEE Trans. Ind. Inform. 2014, 10, 2180-2191. [CrossRef]

54. Jara, A.J.; Zamora-Izquierdo, M.A.; Skarmeta, A.F. Interconnection Framework for mHealth and Remote Monitoring Based on the Internet of Things. IEEE J. Sel. Areas Commun. 2013, 31, 47-65. [CrossRef]

55. Rasid, M.F.A.; Musa, W.M.W.; Kadir, N.A.A.; Noor, A.M.; Touati, F.; Mehmood, W.; Khriji, L.; Al-Busaidi, A.; Ben Mnaouer, A. Embedded gateway services for Internet of Things applications in ubiquitous healthcare. In Proceedings of the 20142 nd International Conference on Information and Communication Technology (ICoICT), Bandung, Indonesia, 28-30 May 2014; pp. $145-148$.

56. Athaya, T.; Choi, S. An Estimation Method of Continuous Non-Invasive Arterial Blood Pressure Waveform Using Photoplethysmography: A U-Net Architecture-Based Approach. Sensors 2021, 21, 1867. [CrossRef]

57. Dohr, A.; Modre-Opsrian, R.; Drobics, M.; Hayn, D.; Schreier, G. The Internet of Things for Ambient Assisted Living. In Proceedings of the 2010 Seventh International Conference on Information Technology: New Generations, Las Vegas, NV, USA, 12-14 April 2010; pp. 804-809.

58. Puustjarvi, J.; Puustjarvi, L. Automating remote monitoring and information therapy: An opportunity to practice telemedicine in developing countries. In Proceedings of the 2011 IST-Africa Conference Proceedings, Gaborone, Botswana, 11-13 May 2011; pp. 1-9.

59. Hoang, M.L.; Carratù, M.; Paciello, V.; Pietrosanto, A. Body Temperature-Indoor Condition Monitor and Activity Recognition by MEMS Accelerometer Based on IoT-Alert System for People in Quarantine Due to COVID-19. Sensors 2021, 21, 2313. [CrossRef] [PubMed]

60. Ruiz, M.; García, J.; Fernández, B. Body temperature and its importance as a vital constant. Rev. De Enferm. 2009, 32, 44-52.

61. Jian, Z.; Zhanli, W.; Zhuang, M. Temperature measurement system and method based on home gateway. Chin. Pat. 2012, 102, 185.

62. In, Z.L. Patient body temperature monitoring system and device based on Internet of Things. Chin. Pat. 2014, 103, 577-688.

63. Zhang, Q.; Arney, D.; Goldman, J.M.; Isselbacher, E.M.; Armoundas, A.A. Design Implementation and Evaluation of a Mobile Continuous Blood Oxygen Saturation Monitoring System. Sensors 2020, 20, 6581. [CrossRef] 
64. Khattak, H.A.; Ruta, M.; Eugenio Di Sciascio, E. CoAP-based healthcare sensor networks: A survey. In Proceedings of the 2014 11th International Bhurban Conference on Applied Sciences Technology (IBCAST), Islamabad, Pakistan, 14-18 January 2014; pp. 499-503.

65. Larson, E.C.; Goel, M.; Boriello, G.; Heltshe, S.; Rosenfeld, M.; Patel, S.N. SpiroSmart: Using a microphone to measure lung function on a mobile phone. In Proceedings of the 2012 ACM Conference on Ubiquitous Computing, Pittsburgh, PA, USA, 5-8 September 2012; pp. 280-289.

66. Larson, E.C.; Goel, M.; Redfield, M.; Boriello, G.; Rosenfeld, M.; Patel, S.N. Tracking lung function on any phone. In Proceedings of the 3rd ACM Symposium on Computing for Development, Bangalore, India, 11-12 January 2013; pp. 1-2.

67. Livingstone, R.; Paleg, G. Enhancing Function, Fun and Participation with Assistive Devices, Adaptive Positioning, and Augmented Mobility for Young Children with Infantile-Onset Spinal Muscular Atrophy: A Scoping Review and Illustrative Case Report. Disabilities 2021, 1, 1-22. [CrossRef]

68. Fan, Y.J.; Yin, Y.H.; Xu, L.D.; Zeng, Y.; Wu, F. IoT-Based Smart Rehabilitation System. IEEE Trans. Ind. Inform. 2014, 10, 1568-1577.

69. Tan, B.; Tian, O. Short paper: Using BSN for tele-health application in upper limb rehabilitation. In Proceedings of the 2014 IEEE World Forum on Internet of Things (WF-IoT), Seoul, Korea, 6-8 March 2014; pp. 169-170.

70. Lin, D. Integrated Internet of Things application system for prison. Chin. Pat. 2013, 102, 236.

71. Guangnan, Z.; Penghui, L. IoT (Internet of Things) control system facing rehabilitation training of hemiplegic patients. Chin. Pat. 2012, 202, 045 .

72. Yue-Hong, Y.; Wu, F.; Jie, F.Y.; Jian, L.; Chao, X.; Yi, Z. Remote medical rehabilitation system in smart city. Chin. Pat. 2014, 103,880 .

73. Liang, S.; Zilong, Y.; Hai, S.; Trinidad, M. Childhood autism language training system and Internet-of-Things-based centralized training center. Chin. Pat. 2011, 102, 661.

74. Hammar, T.; Hamqvist, S.; Zetterholm, M.; Jokela, P.; Ferati, M. Current Knowledge about Providing Drug-Drug Interaction Services for Patients-A Scoping Review. Pharmacy 2021, 9, 69. [CrossRef]

75. Pang, Z.; Tian, J.; Chen, Q. Intelligent packaging and intelligent medicine box for medication management towards the Internetof-Things. In Proceedings of the 16th International Conference on Advanced Communication Technology, Pyeong Chang, Korea, 16-19 February 2014; pp. 352-360.

76. Laranjo, I.; Macedo, J.; Santos, A. Internet of Things for medication control: E-health architecture and service implementation. Int. J. Reliab. Qual. E-Healthc. (IJRQEH) 2013, 2, 1-15. [CrossRef]

77. Khan, M.A.; Zeb, K.; Sathishkumar, P.; Ali, M.U.; Uddin, W.; Hussain, S.; Ishfaq, M.; Khan, I.; Cho, H.G.; Kim, H.J. A Novel Supercapacitor/Lithium-Ion Hybrid Energy System with a Fuzzy Logic-Controlled Fast Charging and Intelligent Energy Management System. Electronics 2018, 7, 63. [CrossRef]

78. Yang, L.; Ge, Y.; Li, W.; Rao, W.; Shen, W. A home mobile healthcare system for wheelchair users. In Proceedings of the 2014 IEEE 18th International Conference on Computer Supported Cooperative Work in Design (CSCWD), Hsinchu, Taiwan, 21-23 May 2014; pp. 609-614.

79. Kolici, V.; Spaho, E.; Matsuo, K.; Caballe, S.; Barolli, L.; Xhafa, F. Implementation of a Medical Support System Considering P2P and IoT Technologies. In Proceedings of the 2014 Eighth International Conference on Complex, Intelligent and Software Intensive Systems, Birmingham, UK, 2-4 July 2014; pp. 101-106.

80. Majumder, S.; Deen, M.J. Smartphone Sensors for Health Monitoring and Diagnosis. Sensors 2019, 19, 2164. [CrossRef]

81. Mosa, A.S.M.; Yoo, I.; Sheets, L. A systematic review of healthcare applications for smartphones. BMC Med. Inform. Decis. Mak. 2012, 12, 67. [CrossRef]

82. White, P.J.F.; Podaima, B.W.; Friesen, M.R. Algorithms for Smartphone and Tablet Image Analysis for Healthcare Applications. IEEE Access 2014, 2, 831-840. [CrossRef]

83. Agu, E.; Pedersen, P.; Strong, D.; Tulu, B.; He, Q.; Wang, L.; Li, Y. The smartphone as a medical device: Assessing enablers, benefits and challenges. In Proceedings of the 2013 IEEE International Conference on Sensing, Communications and Networking (SECON), New Orleans, LA, USA, 24-27 June 2013; pp. 76-80.

84. Rohokale, V.M.; Prasad, N.R.; Prasad, R. A cooperative Internet of Things (IoT) for rural healthcare monitoring and control. In Proceedings of the 2011 2nd International Conference on Wireless Communication, Vehicular Technology, Information Theory and Aerospace Electronic Systems Technology (Wireless VITAE), Chennai, India, 28 February-3 March 2011; pp. 1-6.

85. Coronavirus Cases. Available online: https://www.worldometers.info/coronavirus/ (accessed on 21 May 2020).

86. Davenport, T.; Kalakota, R. The potential for artificial intelligence in healthcare. Future Healthc. J. 2019, 6, 94. [CrossRef]

87. Phillips-Wren, G.; Ichalkaranje, N. Intelligent Decision Making: An AI-Based Approach; Springer Science \& Business Media: Berlin/Heidelberg, Germany, 2008; Volume 97.

88. Matni, N.; Moraes, J.; Pacheco, L.; Rosário, D.; Oliveira, H.; Cerqueira, E.; Neto, A. Experimenting Long Range Wide Area Network in an e-Health Environment: Discussion and Future Directions. In Proceedings of the 2020 International Wireless Communications and Mobile Computing (IWCMC), Limassol, Cyprus, 15-19 June 2020; pp. 758-763. [CrossRef]

89. Alam, M.M.; Malik, H.; Khan, M.I.; Pardy, T.; Kuusik, A.; Le Moullec, Y. A Survey on the Roles of Communication Technologies in IoT-Based Personalized Healthcare Applications. IEEE Access 2018, 6, 36611-36631. [CrossRef]

90. Islam, S.R.; Kwak, D.; Kabir, M.H.; Hossain, M.; Kwak, K.S. The internet of things for health care: A comprehensive survey. IEEE Access 2015, 3, 678-708. [CrossRef] 
91. Yeole, A.S.; Kalbande, D.R. Use of Internet of Things (IoT) in healthcare: A survey. In Proceedings of the ACM Symposium on Women in Research 2016, Indore, India, 21 March 2016; pp. 71-76.

92. Jaiswal, K.; Anand, V. A Survey on IoT-Based Healthcare System: Potential Applications, Issues, and Challenges. In Advances in Biomedical Engineering and Technology; Rizvanov, A.A., Singh, B.K., Ganasala, P., Eds.; Springer: Singapore, 2021 ; pp. $459-471$.

93. Alshehri, F.; Muhammad, G. A Comprehensive Survey of the Internet of Things (IoT) and AI-Based Smart Healthcare. IEEE Access 2021, 9, 3660-3678. [CrossRef]

94. Javaid, M.; Khan, I.H. Internet of Things (IoT) enabled healthcare helps to take the challenges of COVID-19 Pandemic. J. Oral Biol. Craniofac. Res. 2021, 11, 209-214. [CrossRef] [PubMed]

95. Rozas, A.; Araujo, A.; Rabaey, J.M. Analyzing the Performance of WBAN Links during Physical Activity Using Real Multi-Band Sensor Nodes. Appl. Sci. 2021, 11, 2920. [CrossRef]

96. Zeng, W.; Gautam, A.; Huson, D.H. On the Application of Advanced Machine Learning Methods to Analyze Enhanced, Multimodal Data from Persons Infected with COVID-19. Computation 2021, 9, 4. [CrossRef]

97. Al-Marsy, A.; Chaudhary, P.; Rodger, J.A. A Model for Examining Challenges and Opportunities in Use of Cloud Computing for Health Information Systems. Appl. Syst. Innov. 2021, 4, 15. [CrossRef]

98. Prime Minister's Smart Lockdown Lauded Globally. Available online: https://tribune.com.pk/story/2256498/prime-ministerssmart-lockdown-lauded-globally (accessed on 21 September 2020).

99. Alosaimi, W.; Ansari, M.T.J.; Alharbi, A.; Alyami, H.; Seh, A.H.; Pandey, A.K.; Agrawal, A.; Khan, R.A. Evaluating the Impact of Different Symmetrical Models of Ambient Assisted Living Systems. Symmetry 2021, 13, 450. [CrossRef]

100. Shahamabadi, M.S.; Ali, B.B.M.; Varahram, P.; Jara, A.J. A Network Mobility Solution Based on 6LoWPAN Hospital Wireless Sensor Network (NEMO-HWSN). In Proceedings of the 2013 Seventh International Conference on Innovative Mobile and Internet Services in Ubiquitous Computing, Taichung, Taiwan, 3-5 July 2013; pp. 433-438.

101. Zhang, X.M.; Zhang, N. An Open, Secure and Flexible Platform Based on Internet of Things and Cloud Computing for Ambient Aiding Living and Telemedicine. In Proceedings of the 2011 International Conference on Computer and Management (CAMAN), Wuhan, China, 19-21 May 2011; pp. 1-4.

102. Istepanian, R.S.H. The potential of Internet of Things (IoT) for assisted living applications. In Proceedings of the IET Seminar on Assisted Living 2011, London, UK, 6 April 2011; pp. 1-40.

103. Goncalves, F.; Macedo, J.; Nicolau, M.J.; Santos, A. Security architecture for mobile e-health applications in medication control. In Proceedings of the 2013 21st International Conference on Software, Telecommunications and Computer Networks-(SoftCOM 2013), Split-Primosten, Croatia, 18-20 September 2013; pp. 1-8.

104. Kang, J.J.; Dibaei, M.; Luo, G.; Yang, W.; Haskell-Dowland, P.; Zheng, X. An Energy-Efficient and Secure Data Inference Framework for Internet of Health Things: A Pilot Study. Sensors 2021, 21, 312. [CrossRef]

105. Istepanian, R.S.H.; Jovanov, E.; Zhang, Y.T. Guest Editorial Introduction to the Special Section on M-Health: Beyond Seamless Mobility and Global Wireless Health-Care Connectivity. IEEE Trans. Inf. Technol. Biomed. 2004, 8, 405-414. [CrossRef]

106. U.S. Food and Drug Administration. Guidance for industry, E6 good clinical practice: Consolidated guidance. Fed. Regist. 1997, 10, 691-709.

107. Shen, Z.; Spruit, M. Automatic Extraction of Adverse Drug Reactions from Summary of Product Characteristics. Appl. Sci. 2021, 11, 2663. [CrossRef]

108. Jara, A.J.; Belchi, F.J.; Alcolea, A.F.; Santa, J.; Zamora-Izquierdo, M.A.; Gómez-Skarmeta, A.F. A Pharmaceutical Intelligent Information System to detect allergies and Adverse Drugs Reactions based on internet of things. In Proceedings of the 2010 8th IEEE International Conference on Pervasive Computing and Communications Workshops (PERCOM Workshops), Mannheim, Germany, 29 March-2 April 2010; pp. 809-812.

109. Zheng, S.; Zhang, X.; Greuter, M.J.W.; de Bock, G.H.; Lu, W. Determinants of Population-Based Cancer Screening Performance at Primary Healthcare Institutions in China. Int. J. Environ. Res. Public Health 2021, 18, 3312. [CrossRef] [PubMed]

110. You, L.; Liu, C.; Tong, S. Community Medical Network (CMN): Architecture and implementation. In Proceedings of the 2011 Global Mobile Congress, Shanghai, China, 17-18 October 2011; pp. 1-6.

111. Wang, W.; Li, J.; Wang, L.; Zhao, W. The internet of things for resident health information service platform research. In Proceedings of the IET International Conference on Communication Technology and Application (ICCTA 2011), Beijing, China, 14-16 October 2011; pp. 631-635.

112. Cohen, J.F.W.; Hecht, A.A.; McLoughlin, G.M.; Turner, L.; Schwartz, M.B. Universal School Meals and Associations with Student Participation, Attendance, Academic Performance, Diet Quality, Food Security, and Body Mass Index: A Systematic Review. Nutrients 2021, 13, 911. [CrossRef]

113. Vicini, S.; Bellini, S.; Rosi, A.; Sanna, A. An internet of things enabled interactive totem for children in a living lab setting. In Proceedings of the 2012 18th International ICE Conference on Engineering, Technology and Innovation, Munich, Germany, 18-20 June 2012; pp. 1-10.

114. Vazquez-Briseno, M.; Navarro-Cota, C.; Nieto-Hipolito, J.I.; Jimenez-Garcia, E.; Sanchez-Lopez, J.D. A proposal for using the internet of things concept to increase children's health awareness. In Proceedings of the CONIELECOMP 2012, 22nd International Conference on Electrical Communications and Computers, Cholula, Puebla, Mexico, 27-29 February 2012; pp. 168-172. 
115. Chung, W.-Y.; Lee, Y.-D.; Jung, S.-J. A wireless sensor network compatible wearable u-healthcare monitoring system using integrated ECG, accelerometer and SpO2. In Proceedings of the 2008 30th Annual International Conference of the IEEE Engineering in Medicine and Biology Society, Vancouver, BC, Canada, 20-25 Augest 2008; pp. 1529-1532.

116. Castillejo, P.; Martinez, J.; Rodriguez-Molina, J.; Cuerva, A. Integration of wearable devices in a wireless sensor network for an E-health application. IEEE Wirel. Commun. 2013, 20, 38-49. [CrossRef]

117. Bazzani, M.; Conzon, D.; Scalera, A.; Spirito, M.A.; Trainito, C.I. Enabling the IoT Paradigm in E-health Solutions through the VIRTUS Middleware. In Proceedings of the 2012 IEEE 11th International Conference on Trust, Security and Privacy in Computing and Communications, Liverpool, UK, 25-27 June 2012; pp. 1954-1959.

118. Lopez, P.; Fernandez, D.; Jara, A.J.; Skarmeta, A.F. Survey of Internet of Things Technologies for Clinical Environments. In Proceedings of the 2013 27th International Conference on Advanced Information Networking and Applications Workshops, Barcelona, Spain, 25-28 March 2013; pp. 1349-1354.

119. Ghazi, M.; Rippetoe, J.; Chandrashekhar, R.; Wang, H. Focal Vibration Therapy: Vibration Parameters of Effective Wearable Devices. Appl. Sci. 2021, 11, 2969. [CrossRef]

120. Bertrand, S.; Meynet, G.; Taffé, P.; Della Santa, V.; Fishman, D.; Fournier, Y.; Frochaux, V.; Ribordy, V.; Rutschmann, O.T.; Hugli, O. Opiophobia in Emergency Department Healthcare Providers: A Survey in Western Switzerland. J. Clin. Med. 2021, 10, 1353. [CrossRef]

121. Lee, K.S.; Kim, H.I.; Kim, H.Y.; Cho, G.J.; Hong, S.C.; Oh, M.J.; Kim, H.J.; Ahn, K.H. Association of Preterm Birth with Depression and Particulate Matter: Machine Learning Analysis Using National Health Insurance Data. Diagnostics 2021, 11, 555. [CrossRef]

122. Nakamura, E.F.; Loureiro, A.A.F.; Frery, A.C. Information Fusion for Wireless Sensor Networks: Methods, Models, and Classifications. ACM Comput. Surv. 2007, 39, 9. [CrossRef]

123. Herrmann, P. Trust-based protection of software component users and designers. In International Conference on Trust Management; Springer: Berlin/Heidelberg, Germany, 2003; pp. 75-90.

124. Loop-Free KNN Algorithm for GNU Octave and Matlab. Available online: https://github.com/markuman/fastKNN (accessed on 22 February 2021).

125. Philip, R. How IoT Will Help Medical Connectivity during the covid-19 Pandemic. Available online: https://bdtechtalks.com/ 2020/08/15/iot-medical-connectivity-covid-19/ (accessed on 29 September 2020).

126. Singapore to Make Travellers Wear Electronic Tags to Enforce Quarantine. Available online: https://www.reuters.com/article/ us-health-coronavirus-singapore-wearable-idUSKBN24Z0D9 (accessed on 29 September 2020).

127. Liang, S.H.L.; Saeedi, S.; Ojagh, S.; Honarparvar, S.; Kiaei, S.; Mohammadi Jahromi, M.; Squires, J. An Interoperable Architecture for the Internet of COVID-19 Things (IoCT) Using Open Geospatial Standards-Case Study: Workplace Reopening. Sensors 2021, 21, 50. [CrossRef] 